\title{
Testing the function of dromaeosaurid (Dinosauria, Theropoda) 'sickle claws' through musculoskeletal modelling and optimization
}

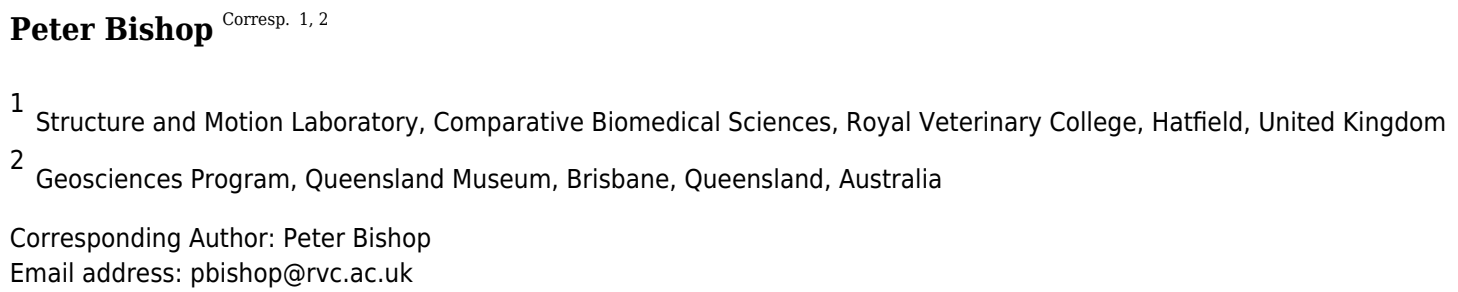

Dromaeosaurids were a clade of bird-like, carnivorous dinosaurs that are well known for their characteristic morphology of pedal digit II, which bore an enlarged, sickle-shaped claw and permitted an extreme range of flexion-extension. Proposed functions for the claw often revolve around predation, but the exact manner of use varies widely. Musculoskeletal modelling provides an avenue to quantitatively investigate the biomechanics of this enigmatic system, and thereby test different behavioural hypotheses. Here, a musculoskeletal model of the hindlimb and pes of Deinonychus was developed, and mathematical optimization was used to assess the factors that maximize production of force at the claw tip. Optimization revealed that more crouched hindlimb postures (i.e., more flexed knees and ankles) and larger flexor muscle volumes consistently increased claw forces, although the optimal degree of digit flexion or extension depended on assumptions of muscle activity and fibre operating range. Interestingly, the magnitude of force capable of being produced at the claw tip was relatively small, arguing against regular transmission of a large proportion of body weight into a substrate principally via the claw tip. Such transmission would therefore likely have needed to occur via more proximal parts of the foot. Collectively, the results best support a grasping function for digit II (e.g., restraint of prey smaller than the dromaeosaurid's own body size), although other behaviours involving flexed hindlimbs cannot be excluded. 
1 Testing the function of dromaeosaurid (Dinosauria,

2 Theropoda) 'sickle claws' through musculoskeletal

3 modelling and optimization

4

5 P.J. Bishop ${ }^{1,2}$

6

${ }^{1}$ Structure and Motion Laboratory, Comparative Biomedical Sciences, Royal Veterinary College,

Hatfield, United Kingdom.

${ }^{2}$ Geosciences Program, Queensland Museum, Brisbane, Australia.

10

11 Corresponding email: pbishop@rvc.ac.uk.

12

13

14

15

16

17

18

19

20

21

22

23

24

25

26

27

28

Page $\mathbf{1}$ of $\mathbf{3 1}$ 


\section{$29 \underline{\text { Abstract }}$}

31 Dromaeosaurids were a clade of bird-like, carnivorous dinosaurs that are well known for their

32 characteristic morphology of pedal digit II, which bore an enlarged, sickle-shaped claw and permitted an extreme range of flexion-extension. Proposed functions for the claw often revolve

34 around predation, but the exact manner of use varies widely. Musculoskeletal modelling provides an avenue to quantitatively investigate the biomechanics of this enigmatic system, and thereby test different behavioural hypotheses. Here, a musculoskeletal model of the hindlimb and pes of Deinonychus was developed, and mathematical optimization was used to assess the factors that maximize production of force at the claw tip. Optimization revealed that more crouched hindlimb postures (i.e., more flexed knees and ankles) and larger flexor muscle volumes consistently increased claw forces, although the optimal degree of digit flexion or extension depended on assumptions of muscle activity and fibre operating range. Interestingly, the magnitude of force capable of being produced at the claw tip was relatively small, arguing against regular transmission of a large proportion of body weight into a substrate principally via the claw tip.

44 Such transmission would therefore likely have needed to occur via more proximal parts of the foot. Collectively, the results best support a grasping function for digit II (e.g., restraint of prey smaller than the dromaeosaurid's own body size), although other behaviours involving flexed

47 hindlimbs cannot be excluded. 


\section{Introduction}

60

61

62

Dromaeosaurids were a long-lived, geographically widespread and highly diverse clade of smallto medium-sized theropod dinosaurs that were very closely related to birds (Norell \& Makovicky 2004; Turner et al. 2012; Turner et al. 2007). One of the most striking anatomical features of this group is a highly modified pedal digit II (second toe), the likes of which are not observed in any living species. Specifically, the articular facets of the first and second phalanges enabled extreme digit hyperextension, in addition to strong digit flexion, and the ungual (claw) was larger and more strongly curved than those of the other pedal digits (Fig. 1A; Norell \& Makovicky 1997; Norell \& Makovicky 2004; Ostrom 1969b; Senter 2009; Turner et al. 2012). This morphology is also present in troodontids, which are often recognized as the sister group to dromaeosaurids (Turner et al. 2012), although see Godefroit et al. (2013) for a different interpretation. In phylogenetically derived dromaeosaurids (eudromaeosaurs) such as Deinonychus, Velociraptor and Utahraptor, the ungual of digit II becomes further enlarged and sickle-shaped, in association with relative shortening of the metatarsus (Ostrom 1976; Turner et al. 2012).

Owing to its unique morphology and mobility, the function of pedal digit II has featured prevalently in discussions of dromaeosaurid palaeobiology, especially predation. In this context, it is useful to define (relative) prey size categories following the prior framework of Fowler et al. (2009, 2011). Specifically, 'small' prey is able to be contained entirely within the foot (encircled by flexed digits and claws); 'large' prey is too large to be able to be contained within the foot, but can be held down by the predator's body weight; 'very large' prey is too large to be held down by the predator's own weight. A wide variety of hypotheses have been proposed for the how digit II was used in life, which include:

1. Used in combination with kicking behaviour of one hindlimb (while balancing on the other limb) to cut, slash or disembowel prey (Fig. 1B; Adams 1987; Ostrom 1969b; Ostrom 1990); the prey animal is often presumed to be of very large body size.

2. After leaping onto the flanks of a very large prey animal, the claws are used to pierce and grip the hide of the prey, allowing the predator to hold onto struggling prey and position itself appropriately for delivering bites (Fig. 1C; Manning et al. 2009; Manning et al. 2006). The 
efficacy of this technique is supported by analogy with the curved manual claws of felids (Bryant et al. 1996) and was also demonstrated using a life-sized physical model by Manning et al. (2006), although Fowler et al. (2011) raised concerns over the latter study’s model accuracy.

3. After leaping onto the flanks of a prey animal (which again is of very large size), the predator uses its body weight to drive the claws into and down the sides of the prey to inflict large wounds (Fig. 1D; Henderson 2012). A variant of this is where the predator actively employs a kicking and slashing action whilst on the prey's flanks (Paul 1988).

4. The claw is used to pierce or slash specific parts of the prey, targeting vital areas such as the blood vessels or trachea in the neck (Fig. 1E; Carpenter 1998). This is often inferred to be the case in the famous 'fighting dinosaurs' specimen of a Velociraptor preserved alongside a Protoceratops (Barsbold 2016; Carpenter 1998; Kielan-Jaworowska \& Barsbold 1972).

5. The claws are used to help pin down and restrain prey of small or large size, allowing it to be attacked and dismembered by the mouth and forelimbs (Fig. 1F; Fowler et al. 2011). The morphology of the claws and feet in many dromaeosaurids is consonant with a gripping or grasping function (Fowler et al. 2011).

6. Used in defence, such as by kicking as often used by various extant birds (Fig. 1G; Colbert \& Russell 1969; Senter 2009), although whether this occurred during inter- or intraspecific interactions has not been specified.

7. Used in a digging action to extract small prey from nests or burrows, possibly involving a 'hook and pull' motion of a strongly flexed digit (Fig. 1H; Colbert \& Russell 1969; Senter 2009; Simpson et al. 2010).

It is worth noting that the different proposed behaviours involve both markedly different degrees of digit flexion-extension and different whole-limb postures. In contrast to the uncertainty surrounding how digit II was used, however, it is widely agreed that when not in use (e.g., locomotion) it was held in a retracted (extended) state, with the claw held off the ground as illustrated in Fig. 1A. This is supported by numerous didactyl and narrow-gauge bipedal fossil trackways of Mesozoic age, for which dromaeosaurids or troodontids are the only reasonable makers (e.g., Li et al. 2008; Lockley et al. 2016; Xing et al. 2018; Xing et al. 2015; traces of the distal end of digit II are almost always absent). It is also consistent with osteological range of 
120 motion (e.g., Colbert \& Russell 1969; Currie \& Peng 1993; Ostrom 1969b; Paul 1988; Senter

121 2009) and articulated fossil specimens (e.g., Csiki et al. 2010; Norell \& Makovicky 1997; Xu et

122 al. 2003).

123

124 One aspect of digit II function in dromaeosaurids that has received little attention is the

125

126

127

128

129

130

131

132

133

134

135

136

137

138

139

140

141

142

143

144

145

146

147

148

149

musculoskeletal mechanism (or mechanisms) that underpinned claw use. In particular, the extreme range of motion that digit II was apparently capable of implies substantial changes in length of the musculotendon units (MTUs) that actuated the claw across the range of flexionextension. This may have had important consequences for force production capacity, as the amount of force that a muscle can actively develop depends on how stretched or contracted its constituent fibres are Turner et al. 2007(Fig. 2; McMahon 1984; Millard et al. 2013; Zajac 1989). In addition to this, force can also be passively produced, both through stretch of the muscle fibres and connective tissues and stretch of the in-series tendon. Thus, the force-length relationships of muscle and tendon may constrain the kinds of digit and whole-limb postures at which maximal claw force could have been attained, and in turn influence the manner in which the claw was used in life.

Computational modelling of the musculoskeletal system provides a robust and quantitative means of addressing this question, and in turn provides an avenue to investigating the function of digit II in dromaeosaurids. Previously, musculoskeletal models have shed insight on diverse palaeobiological topics, including muscle leverage (e.g., Bates et al. 2012; Bates \& Schachner 2012; Hutchinson et al. 2008; Hutchinson et al. 2007; Maidment et al. 2014), bite forces (e.g., Bates \& Falkingham 2012; Bates \& Falkingham 2018; Lautenschlager et al. 2016), posture and locomotion (e.g., Bates et al. 2012; Bishop et al. 2018; Hutchinson et al. 2005; Nagano et al. 2005; Sellers et al. 2017). The present study developed a musculoskeletal model of the dromaeosaurid hindlimb to examine how the force-length relationships of muscle and tendon may influence claw force production. Framing the question as an optimization problem, the aim was to determine the combination of factors (including digit and limb posture) that maximize claw force, with the view to testing the aforementioned hypotheses of how digit II was used in life. In addition to addressing the specific question of claw use in dromaeosaurids, this study also

Page 5 of 31

PeerJ reviewing PDF | (2019:05:38118:1:2:NEW 3 Jul 2019) 
150 provides a methodological framework that may be adapted and used to address other

151 palaeobiological questions in the future.

152

153

154

Methods

155

Approach of the current study

157

Before the specific methodological details are presented in full, the key premises and assumptions of the current study are outlined here.

160

Optimization

162 The highly modified osteology of pedal digit II, in concert with the inference that it was not used 163 in locomotion ( $\mathrm{Li}$ et al. 2008; Lockley et al. 2016; Xing et al. 2018; Xing et al. 2015), suggests

164 that it was used for a very specific purpose in life. Musculotendon anatomy was therefore

165 probably quite highly adapted ('tuned') for that single purpose, in contrast to other muscles in the 166 hindlimb which would be required to execute many different activities (see Hutchinson et al.

167 2015). As such, the question of dromaeosaurid digit II function can be approached via the 168 methods of mathematical optimization. That is, the goal is to relate how claw force varies with 169 musculotendon anatomy, digit flexion and whole-limb posture, to identify the circumstances in which the force produced at the claw tip is maximized.

171

$172 \underline{\text { Statics }}$

173 Common to each of the proposed hypotheses for dromaeosaurid digit II use (Fig. 1B-H) is an 174 implicit assumption that the force applied by the claw to the substrate (e.g., prey) is of greater 175 importance than the speed at which the claw tip moves with respect to more proximal limb 176 segments (e.g., metatarsus). As a consequence, all simulations in the present study were static 177 only; this assumption also helped to make the system more tractable for analysis and serves as a 178 useful starting point that may be built upon in the future. 
180

181

182

183

184

185

186

187

188

189

190

191

192

193

194

195

196

197

198

199

200

201

202

203

204

205

206

207

208

209

$\underline{\text { Musculature }}$

During claw use, regardless of the source of the force being applied through the claw (e.g., intrinsic flexor musculature of digit II, more proximal muscles in the hindlimb, body weight, limb inertia), the muscle that flexed the claw itself would have to be capable of matching or exceeding these forces. Otherwise, upon encountering reaction forces from the substrate, the claw (and possibly also more proximal parts of digit II) would undergo relative extension, diminishing its effectiveness. It is likely that multiple muscles (both flexor and extensor) would have actuated digit II in life. The extant phylogenetic bracket (Witmer 1995) of dromaeosaurids, crocodilians and birds, possess multiple digital flexors and multiple digital extensors in the hindlimb (Allen et al. 2015; Baumel et al. 1993; Cong 1998; George \& Berger 1966). However, aside from the flexor digitorum longus and extensor digitorum longus, the homology of these muscles among archosaurs remains unclear (Carrano \& Hutchinson 2002; Hutchinson 2002). Dromaeosaurids were probably capable of controlling flexion-extension of digit II independent of the other digits, as suggested by previously proposed behavioural hypotheses and their inferred ability to retract the digit when it was not in use. Hence, any muscles that actuated digit II would have been separate from those actuating other digits; as the flexor digitorum longus and extensor digitorum longus are the only muscles to attach to the ungual in extant archosaurs, dromaeosaurids may therefore be inferred to have had at the very least separate digit II derivatives of the flexor and extensor digitorum longus. These two muscles would have been the two most important muscles in digit II: if they were not strong enough to actuate the claw appropriately, then the digit's function would be diminished. As such, in the current study only a single flexor and extensor muscle were modelled, attaching to their respective tubercle on the ungual; these are responsible for actuating the entire digit. This simplifying assumption again helps make the system more tractable and can be built upon in future analyses.

\section{$\underline{\text { Digit II retraction }}$}

As noted above, dromaeosaurids are inferred to have held digit II in a retracted state when it was not in use. The mechanism by which this was achieved may have an important influence on musculotendon behaviour when the claw was in use, and so is deserved of careful consideration. There are at least four possible ways in which digit II was retracted above the ground: 
210

211

212

213

214

215

216

217

218

219

220

221

222

223

224

225

226

227

228

229

230

231

232

233

234

235

236

237

238

239

240

1. Snap ligaments that spanned the metatarsophalangeal and interphalangeal joints, which were engaged when the digit was retracted beyond a certain point (effected by active contraction of extensor musculature), upon which the digit would be passively held in place (Manning et al. 2006). This is analogous to the retractable claws of felids (Bryant et al. 1996; Gonyea \& Ashworth 1975).

2. In a similar fashion to the digital flexor tendons of many extant neognath birds, the extensor musculature of digit II possessed a 'tendon locking mechanism' (Einoder \& Richardson 2006; Einoder \& Richardson 2007; Quinn \& Baumel 1990) that involved a ratchet-like interaction between the tendon(s) and the surrounding sheath(s). This is functionally similar to snap ligaments, in that active muscle contraction engages the mechanism, upon which the digit is passively held in a retracted state. (See also Manning et al. (2009), who considered the possibility of a tendon locking mechanism in the flexor tendons that may have assisted with prey apprehension.)

3. The extensor musculature was constantly active, producing force that continually held the digit in a retracted state. When the musculature ceased firing, the digit would flex under its own weight (and possibly due to passive elasticity in stretched flexor musculature) back to an unretracted state.

4. The normal resting lengths of the flexor and extensor muscles were such that the digit was elevated above the ground when the muscles were inactive. That is, the weight of the digit (causing the digit to flex downward) was counteracted by passive elasticity in the extensor muscle and tendon (causing the digit to extend upward). This is functionally analogous to 'tenodesis grasp' in humans, where passive flexing of the digits occurs when the wrist undergoes extension (Mateo et al. 2013).

Each of the above mechanisms is speculative to some degree. There is no osteological evidence of snap ligaments in the pedes of non-avian theropods, nor are they known in the pedes of extant crocodilians or birds. Osteological evidence is also lacking for a tendon locking mechanism (although admittedly this would be difficult to detect, even in extant taxa), and among extant archosaurs it is only known among neognath birds. Hence, inferring the existence of mechanisms 1 or 2 in dromaeosaurids is highly speculative; at best, a level II' inference in the scheme of Witmer (1995). Mechanisms 3 and 4 are less speculative in that they do not require any specialized anatomical adaptations; of the two, mechanism 4 is the less energetically demanding, 
241 being entirely passive in nature. It is therefore deemed that mechanism 4 provides the most

242 plausible strategy to maintaining digit II in a retracted state when not in use; this forms the basis

243 for a constraint implemented in the optimizations (below).

244

245

246

247

248

249

250

251

252

253

254

255

256

257

258

259

260

261

262

263

264

265

266

267

268

269

270

271

\section{Musculoskeletal modelling}

A three-dimensional (3-D) musculoskeletal model of the hindlimb and pes of Deinonychus antirrhopus was used as the basis of the current study (Fig. 3). Deinonychus, which means 'terrible claw' (Ostrom 1969a), was a relatively large (up to $3 \mathrm{~m}$ and $170 \mathrm{~kg}$; Turner et al. 2007) dromaeosaurid that lived in the Early Cretaceous of North America, and has been frequently studied with respect to dromaeosaurid palaeobiology (e.g., Fowler et al. 2011; Gignac et al. 2010; Gishlick 2001; Ostrom 1969b; Ostrom 1994). The geometry of the pes skeleton was acquired through X-ray computed tomographic scanning (Toshiba Aquilion 64, $135 \mathrm{kV}$ peak tube voltage, $250 \mathrm{mAs}$ exposure, $750 \mathrm{~ms}$ exposure time, $0.5 \mathrm{~mm}$ slice thickness, $0.625 \mathrm{~mm}$ pixel resolution) of a complete articulated pes, specimen MOR 747 (Museum of the Rockies, Bozeman, USA). The resulting scans were segmented using Mimics 17.0 (Materialize NV, Leuven, Belgium) to produce surface meshes, which were then refined in 3-matic 9.0 (Materialize NV, Leuven, Belgium) and ReMESH 2.1 (Attene \& Falcidieno 2006). More proximal limb bones were sculpted digitally using Rhinoceros 4.0 (McNeel, Seattle, USA) based on comparison to the literature (e.g., Ostrom 1969b; Ostrom 1976), and were scaled appropriately with respect to the pes.

The musculoskeletal model was constructed in NMSBuilder (Martelli et al. 2011; Valente et al. 2014) for use in OpenSim 3.3 (Delp et al. 2007). All joints were assigned a single degree of freedom only, with the rotation axis fixed with respect to the 'parent' body in all cases. As the proximal limb bone geometries were sculpted, the knee and ankle joint axes were a priori set as parallel to the global $y$-axis (mediolateral axis). The axes of the first and second interphalangeal (IP) joints of digit II were determined in 3-matic, by fitting a cylinder to the outer margins of the ginglymoid parts of the articular surfaces of the proximal bone involved, with the axis of the cylinder taken to be the axis of rotation. Due to the strong asymmetry of the metatarsophalangeal 
272 (MTP) joint of digit II, motion at this joint was modelled with a helical axis, with coupled

273 rotation about and translation along the axis. The location, orientation and amount of translation

274 per unit rotation of the helical axis was determined with the KineMat toolbox (Reinschmidt \&

275 van den Bogert 1997; see also Spoor \& Veldpaus 1980) for MATLAB 9.5 (MathWorks, Natick,

276 USA), using three landmarks located on phalanx II-1 at pre-determined positions of maximum

277 flexion and extension with respect to metatarsal II. Subsequent visual inspection of the helical

278 motion in OpenSim indicated that the resulting movement was satisfactory, keeping the distance

279 between opposing articular surfaces approximately constant across the area of articulation. The

280 ranges of motion assigned to the MTP and IP joints were based on preserved articular surface

281 geometry, and included the range hypothesized by previous studies (e.g., Ostrom 1969b; Senter

282 2009). So as to simplify the system for analysis, the motions of the two IP joints were

283 programmatically coupled to that of the MTP joint in the model. That is, the angles of the two IP

284 joints were functions of the MTP joint angle, such that only a single degree of freedom (MTP

285 joint angle) was required to describe all three joints that effected digit flexion or extension. The

286 coupling of motions between joints was linear, and was defined by the points of maximum

287 flexion and extension for each joint:

$$
\theta_{\mathrm{IP} 1}=1.04211 \times \theta_{\mathrm{MTP}}+39.75756 \text {, }
$$

$$
\theta_{\mathrm{IP} 2}=0.69474 \times \theta_{\mathrm{MTP}}-3.49496 \text {, }
$$

where $\theta_{\mathrm{IP} 1}, \theta_{\mathrm{IP} 2}$ and $\theta_{\mathrm{MTP}}$ are the first IP, second IP and MTP joint angles, respectively, measured in degrees. Ultimately, this meant that the digit was capable of $125^{\circ}$ of motion $\left(-65^{\circ}\right.$ flexion to $60^{\circ}$ extension; Fig. 3D).

As noted above, only a single flexor and a single extensor muscle were modelled, which are inferred to be derivatives of the flexor digitorum longus and extensor digitorum longus, respectively. These muscles exhibit disparate origins among extant archosaurs: in crocodylians they both originate from the distal femur, whereas in birds they originate from the proximal tibia (Allen et al. 2015; Baumel et al. 1993; Cong 1998; George \& Berger 1966). As such, two geometric variants of both muscles' MTU actuators were used: a 'short' version that originated from the proximal tibia, and a 'long' version that originated from the distal femur (Fig. 3C). The 3-D course of the MTUs were constrained to follow anatomically realistic paths across the 
302 model's entire range of motion, using a combination of via points and cylindrical or toroidal

303 wrapping surfaces (Fig. 3A; (Delp et al. 1990; Garner \& Pandy 2000)); the courses of the short

304

305

306

307

308

309

310

311

312

313

314

315

316

317

318

319

320

321

322

323

324

325

326

327 Given

328

329

330 thus:

and long MTUs were identical from the distal tibia onwards towards the ungual.

Insofar as the MTUs were concerned, the musculoskeletal model was used only to provide information on geometrical relationships, namely, how MTU lengths and moment arms varied with respect to joint angle. The actual modelling of MTU activation-contraction dynamics was undertaken in MATLAB, using the formulation of De Groote et al. (2016). This formulation is a Hill-type model (see Fig. 2A) that uses an implicit representation of activation-contraction dynamics with tendon force as a state variable, and which is computationally robust and conducive to efficient numerical optimization (e.g., by enabling algorithmic differentiation). The musculoskeletal model was also used to calculate the moment about the MTP joint due to the weight of the digit at a given MTP angle (used in the constraints described below). Mass properties of each digit segment were defined by first modelling the soft tissues with basic geometries (elliptical frusta or cylinders) in Rhinoceros, and then assigning a bulk density to each segment $\left(1,000 \mathrm{~kg} / \mathrm{m}^{3}\right.$ for phalanges II-1 and II-2; $1,500 \mathrm{~kg} / \mathrm{m}^{3}$ for the ungual).

\section{Optimization}

For simplicity, all optimization simulations in the present analysis were static only. The musculoskeletal model was used to identify the circumstances in which the force produced at the claw tip is maximized. The optimization problem was solved for each MTP angle and was posed

$$
F_{\text {flex }}=f\left(1_{\mathrm{O}, \text { flex }}, L_{\mathrm{S}, \text { flex }}, \alpha_{\mathrm{O}, \text { flex }}, F_{\text {max }, \text { flex }}, a_{\text {flex }}, l_{\text {flex }}\right)
$$

$$
l_{\text {flex }}=f\left(\theta_{\mathrm{MTP}}, \text { posture }\right)
$$$$
l_{\mathrm{ext}}=f\left(\theta_{\mathrm{MTP}}, \text { posture }\right)
$$ 
331

332

333

334

335

336

337

338 Subject to

340

341

342

343

344

345

346

347

348

349

350

351

352

353

354

355

Optimize

Subject to

0

$$
\begin{gathered}
r_{\text {flex, MTP }}=f\left(\theta_{\mathrm{MTP}}\right) \\
r_{\text {ext, MTP }}=f\left(\theta_{\mathrm{MTP}}\right) \\
r_{\text {flex, IP2 }}=f\left(\theta_{\mathrm{MTP}}\right) \\
r_{\text {ext, IP2 }}=f\left(\theta_{\mathrm{MTP}}\right)
\end{gathered}
$$

$$
\max \left(F_{\text {claw }}\right)=\frac{F_{\text {flex }}^{a=1} \cdot r_{\text {flex, IP2 }}+F_{\text {ext }}^{a=0} \cdot r_{\text {ext, IP2 }}}{r_{\text {claw }}}
$$

$$
\begin{gathered}
\lambda_{\text {ext, } \theta_{\mathrm{MTP}}=-65^{\circ}}^{*, a=1} \leq 1.5 \\
\lambda_{\text {ext, } \theta_{\mathrm{MTP}}=60^{\circ}}^{*, a=1} \geq 0.5 \\
F_{\text {flex }}^{a=0} \cdot r_{\text {flex }}^{\theta_{\mathrm{MTP}}=\text { thresh }}+F_{\mathrm{ext}}^{a=0} \cdot r_{\mathrm{ext}}^{\theta_{\mathrm{MTP}}=\text { thresh }} \geq M_{\text {weight }}^{\theta_{\mathrm{MTP}}=\text { thresh }}
\end{gathered}
$$

Equations 3 and 4 denote the models of muscle activation-contraction dynamics; they relate MTU force $(F)$ to optimum fibre length $\left(\ell_{\mathrm{o}}\right)$, tendon resting or slack length $\left(L_{\mathrm{s}}\right)$, pennation angle at optimum fibre length $\left(\alpha_{\mathrm{o}}\right)$, maximum isometric force $\left(F_{\max }\right)$, activation $(a)$ and MTU length $(l)$,

47 with the subscripts of 'flex' or 'ext' referring to flexor and extensor MTUs, respectively.

48 Equations 5-10 describe the geometric aspects of the system as represented by the

49 musculoskeletal model. Equations 5 and 6 describe how MTU length varies as a function of

MTP angle $\left(\theta_{\mathrm{MTP}}\right)$ and whole-limb posture, whilst equations 7-10 describe how MTU moment 51 arms about a given joint (MTP or second IP) vary as a function of MTP angle.

Equation 11 is the objective function which is to be maximized, and describes moment balance about the second IP joint. The flexor MTU is maximally active $(a=1)$, whereas the extensor MTU is quiescent $(a=0)$ and can only exert force passively, and $r_{\text {claw }}$ is the perpendicular 
356 distance from the axis of rotation of the IP2 joint to the claw tip, which was determined in

357 Rhinoceros to be $76 \mathrm{~mm}$.

358

359

360

361

362

363

364

365

366

367

368

369

370

371

372

373

374

375

376

377

378

379

380

381

382

383

384

385

Equations 12-16 denote constraints that must be satisfied. Equations 12-15 stipulate that the normalized fibre lengths of both flexor and extensor MTUs must remain within reasonable operating ranges at maximal activation, lest they are capable of producing little force (Fig. 2B).

The default range assigned here was $0.5 \leq \ell^{*} \leq 1.5$ (Rankin et al. 2016; but see below). Equation 16 describes the tenodesis-like mechanism that was identified above as probably responsible for holding digit II clear of the ground, and stipulates that the musculoskeletal anatomy that optimizes claw function must also be compatible with holding digit II off the ground. It states that, at some threshold angle $\left(\theta_{\mathrm{MTP}}=\right.$ thresh), the sum of the moments of the flexor and extensor MTUs about the MTP joint (produced only through their passive components, i.e., $a=0$ ), equals or exceeds the moment due to weight of the digit ( $\left.M_{\text {weight }}\right)$. If this is true, then the digit will be able to be held aloft at that threshold angle, or at even higher extension angles.

A total of six design variables were optimized: fibre length, tendon slack length and pennation angle, for both flexor and extensor MTUs. During each iteration, the maximum isometric force of the MTUs was recalculated accordingly as

$$
F_{\max }=\frac{V \cdot \sigma \cdot \cos \left(\alpha_{O}\right)}{1_{O}},
$$

where $V$ is muscle belly volume and $\sigma$ is maximum isometric stress, for which a value of 300,000 N/m² was initially used (e.g., Bates \& Falkingham 2012; Hutchinson 2004a; Sellers et al. 2013). Muscle volume was initially set at $25 \mathrm{~cm}^{3}$ for the flexor and $12.5 \mathrm{~cm}^{3}$ for the extensor, as a subjective guess based on the dimensions of the musculoskeletal model. The permissible values for the design variables during the optimization were constrained between lower and upper bounds that were defined on the basis of the geometry of the musculoskeletal model (Table 1). The lower bound for tendon slack length was set as the minimum length achievable by the respective MTU distal to the ankle across all postures (Fig. 3D). The upper bound for tendon slack length was set at $90 \%$ of the minimum length achievable by the MTU across all postures, and varied depending on the MTU length variant used. An overly generous range of permissible values for pennation angle was used $\left(0-60^{\circ}\right)$, which is considerably broader than the range 
386

387

388

389

390

391

392

393

394

395

396

397

398

399

400

401

402

403

404

405

406

407

408

409

410

411

412

413

414

415

416

observed in the digital flexor and extensor muscles of extant archosaurs (typically $20-35^{\circ}$; Allen et al. 2010; Allen et al. 2015; Hutchinson et al. 2015; Lamas et al. 2014; Paxton et al. 2010; Smith et al. 2006). Given that the flexor and extensor muscles of digit II in dromaeosaurids are presumed to have been 'tuned' for executing a single, non-locomotor behaviour, they may potentially have had a markedly different architecture compared to their homologues in extant archosaurs, which are required to execute a variety of different behaviours (locomotor and nonlocomotor; see Hutchinson et al. 2015). It was therefore not considered justified in this case to constrain pennation angles to the same range of values as observed in extant archosaurs - the 'everyanimal' issue of Pagel (1991).

The optimization was implemented in a set of custom MATLAB scripts that used CasADi 3.4.5 (Andersson et al. 2019), a suite of tools for nonlinear optimization and algorithmic differentiation. The relationships between MTU moment arms or lengths and joint angles were derived from the musculoskeletal model and fed directly into the optimization framework, obviating the need to interface with OpenSim, which speeds up computation (e.g., by facilitating algorithmic differentiation) and avoids discontinuities in the optimization problem. All other aspects of the system were implemented directly into the scripts. The optimization used the opensource solver IPOPT 3.12.3 (Wächter \& Biegler 2006), accessed via the CasADi interface.

\section{Sensitivity analysis}

Optimizations were run for a variety of different combinations, to both test different limb postures and assess sensitivity to unknowns in the musculoskeletal model. Three whole-limb postures were tested (Fig. 3B, Table 1), spanning extended through to crouched limb configurations; each of these postures necessitated a different value for the threshold MTP angle in the constraint described by equation 16 (Table 1).Two different lengths of both flexor and extensor MTUs were tested, on account of uncertainty in muscle origin (see above; Fig. 3C).

Lastly, two additional variants in flexor and extensor muscle belly volume were tested for $( \pm 25 \%$ of initial value). A total of 108 different combinations of variants were subject to optimization, which took approximately 8.5 hours to solve using a computer with a $2.4 \mathrm{GHz}$ processor. In 
417 addition, the sensitivity of optimization results was tested for with regards to four further model 418 assumptions. Firstly, normalized fibre lengths of flexor and extensor MTUs were constrained to 419 operate within the more restricted (optimal) range of $0.75 \leq \ell^{*} \leq 1.25$ (affecting equations 12420 15). Secondly, when digit II was not in use, it was now presumed to be held in a retracted state 421 through active contraction of the extensor MTU $(a=0.5$, affecting equation 16). Thirdly, muscle 422 strength was increased by doubling maximum isometric stress to $600,000 \mathrm{~N} / \mathrm{m}^{2}$ (affecting 423 equation 17). Lastly, the upper and lower bounds for pennation angle of both flexor and extensor 424 muscles were restricted to $20-35^{\circ}$, comparable to the range observed in the digital flexor and 425 extensor muscles of extant archosaurs.

426

427

428

$\underline{\text { Results }}$

429

\section{Initial system configuration}

Using the initial set of assumptions about the system, the maximal claw tip force that is possible at each MTP angle is shown in Fig. 4, summarizing all 108 combinations of whole-limb posture, muscle bulk and muscle length. The mean and range shown for a given posture in Fig. 4A is

435 based on the curves for 36 combinations. These curves (and their derived mean and range curves) are not a profile of force versus MTP angle for a given combination of MTU parameters; rather, each curve is the maximal envelope of all force-angle curves for a given combination, as shown in Fig. 4B. That is, in Fig. 4B there are 126 curves, representing the force-angle profile that results from the optimal combination of MTU parameters identified for each degree of MTP flexion-extension $\left(-65^{\circ}\right.$ to $\left.60^{\circ}\right)$; the maximal envelope of these 126 curves contributes one curve to the data summarized in Fig. 4A. Across the 108 combinations tested, claw force is maximized at MTP angles of between -15 to $50^{\circ}$, with a global maximum of $18.9 \mathrm{~N}$ achieved at an angle of $20^{\circ}$, corresponding to modest digit extension. The results are parsed by whole-limb posture in Fig. 4A, by muscle volume in Fig. 4C,D, and by muscle length in Fig. 4E,F. The magnitude of claw force is markedly variable depending on limb posture, muscle bulk and muscle length, and likewise the MTP angle at which maximum claw force is achieved also varies considerably with 
447

448

449

450

451

452

453

454

455

456

457

458

459

460

461

462

463

464

465

466

467

468

469

470

471

472

473

474

475 476

477

respect to these factors. Nevertheless, two clear trends are that more crouched postures (Fig. 4A) and a larger flexor muscle (Fig. 4C) consistently produce higher claw forces.

\section{Optimal MTU parameters}

For each of the 108 combinations tested, the resulting optimal values for the six design variables at each MTP angle are shown in Fig. 5, parsed by posture (see also Figs S1-4). The optimal fibre length $\left(\ell_{\mathrm{o}}\right)$ and tendon slack length $\left(L_{\mathrm{s}}\right)$ of the flexor muscle vary largely in tandem with each other across much of the range of MTP angles, as a consequence of the optimal pennation angle $\left(\alpha_{0}\right)$ being $0^{\circ}$ (i.e., parallel fibred) across this range, particularly for the 'long flexor' combinations (Fig. S3E). Low or zero $\alpha_{\mathrm{o}}$, whilst it decreases the magnitude of maximum muscle force (equation 17), enables the muscle fibres to be longer, allowing them to operate closer to the peak in their force-length curve across a larger range of MTU length change. The results here (i.e., the tendency to retrieve the lowest $\alpha_{\mathrm{o}}$ possible) therefore directly stem from the large range of flexion-extension that digit II is capable of. The manner of variation in the optimal values of $\ell_{\mathrm{o}}, L_{\mathrm{s}}$ and $\alpha_{\mathrm{o}}$ for the extensor muscle is less straightforward, which is possibly due to it having to satisfy more requirements in a passive state (activation $=0$ ). Notably, extensor $L_{\mathrm{s}}$ tended toward the lower bounds for allowable values over much of the range of MTP angles, which may be related to the requirement for passive tendon stretch contributing toward holding digit II off the ground; a lower $L_{\mathrm{s}}$ produces more passive force for the same absolute amount of stretch. Additionally, across at least part of the range of MTP angles, the optimal value for extensor $\alpha_{0}$ reached the lower or upper bounds of the permissible range of angles. As with claw force, the optimal values of the MTU parameters can vary considerably: for a given MTP angle, they can vary depending on limb posture, muscle volume and muscle length, and for a given combination of limb posture, muscle volume and muscle length, they can vary depending on the MTP angle. In addition to posture having a pronounced effect on the optimal MTU values (Fig. 5), muscle length also has a distinct influence on the optimal values retrieved (Figs S3,4), with flexor length affecting flexor MTU parameters, and vice versa for the extensor, but little 'cross muscle' effects. 


\section{Sensitivity analysis}

479

480

Paralleling the results for the initial system configuration (Fig. 4), in all sensitivity tests

481 conducted it was found that more crouched postures consistently led to higher claw forces being achieved, especially for more flexed digit postures (Fig. 6). Compared to the results for the initial configuration, constraining normalized fibre lengths to a more restricted operating range produced a very different pattern for optimal claw force versus MTP angle (Fig. 6A). In addition to reducing the magnitude of maximal claw force $(-32.1 \pm 3.5 \%$; mean \pm s.d. $)$, this resulted in the maximum force being consistently achieved at a considerably flexed digit posture (MTP angle of -37 to $-35^{\circ}$ ). When the extensor muscle was assumed to be actively contracting to hold digit II off the ground when not in use, this also led to a markedly different pattern in the force-angle curves (Fig. 6B), with maximum claw force achieved at modestly flexed through to extended digit postures (MTP angle of -20 to $15^{\circ}$ ). Additionally, the magnitude of maximum claw force was higher $(30.4 \pm 6.6 \%)$ compared to the initial results. Doubling muscle strength had very little effect on the results, beyond roughly doubling the magnitude of claw force $(90.1 \pm 2.9 \%$ increase), which is not surprising (Fig. 6C). Lastly, restricting the bounds on allowable values for $\alpha_{\mathrm{o}}$ during the optimization had little qualitative effect on the results, although claw force magnitudes were slightly reduced (-11.4 $\pm 5.1 \%$; Fig. 6D). Mimicking the result noted above for the initial system configuration, the optimal value for flexor muscle $\alpha_{\mathrm{o}}$ tended towards the lower bounds of allowable values across much of the range of MTP angles, especially for more crouched postures (Fig. S5A); likewise, the optimal value for extensor $\alpha_{\mathrm{o}}$ again reached the lower or upper bounds across at least part of the range of MTP angles (Fig. S5A). This consistent tendency for the optimizer to push against the bounds for $\alpha_{\mathrm{o}}$ justifies the use of a broader range of permissible values in the initial system configuration, beyond the restricted range observed in extant archosaurs. Indeed, in the absence of further physical constraints, these results suggest that flexor and extensor muscle $\alpha_{\mathrm{o}}$ in dromaeosaurids may have evolved to become markedly outside 505 506 
508 Discussion

509

510 This study used musculoskeletal modelling, framed within the context of mathematical

511 optimization, to investigate the factors that maximize pedal digit II claw force in dromaeosaurids,

512 using Deinonychus as a case study. The results in turn can help test between the various

513 hypotheses proposed for how the digit and its claw were used in life. Under the initial set of

514 assumptions about the system, claw force was maximized in a crouched whole-limb posture

515 (posture 3), with a modest $\left(20^{\circ}\right)$ level of digit extension (Fig. 4A). However, different

516 assumptions about the behaviour of the MTUs involved sometimes led to claw force being

517 maximized at more flexed digit postures (Fig. 6).

518

519

520

MTU parameters and behaviour

521

522 Echoing the sentiments of previous studies (e.g., Bates \& Falkingham 2018; Bates et al. 2010;

523 Hutchinson 2004b), the results of this study demonstrate the important influence that MTU

524 parameters can have on the biomechanical performance of a system. For a given MTP joint angle,

525 the optimal values for the MTU parameters sometimes varied considerably, depending on the

526 assumed combination of limb posture, muscle bulk and muscle length (Figs 5, S1-4). Moreover,

527 for a given combination, the optimal MTU parameters often varied depending on the MTP angle

528 under consideration (Figs 5, S1-4). The ability to better constrain the range of plausible values for

529 each MTU parameter will help refine the results obtained here, which remains a key challenge in

530 palaeobiological inquiry.

531

532 Yet, rather than taking a nihilistic view, musculoskeletal modelling provides a unique perspective 533 to addressing these challenges. It can identify those aspects of the system to which the results are 534 most sensitive, and therefore where future research effort should be directed in order to refine 535 understanding further. For instance, muscle bulk (Figs S1,2) and length (Figs 3,4) both exert 536 marked influence on the optimal value for MTU parameters and in turn claw force production;

537 better constraining muscle sizes and origins will help address this. Perhaps the single most 
538 influential aspect identified here was the allowable operating range of the muscle fibres:

539 regardless of every other variant in the system, a more constrained operating range $\left(0.75 \leq \ell^{*} \leq\right.$

540 1.25) resulted in claw force being maximized in a very consistent manner, at moderate levels of

541 digit flexion (compare Fig. 6A with Fig. 4A). Underpinning the approach of the present study is

542 the notion that the system under consideration was highly adapted for a single purpose in life. It

543 is therefore conceivable that muscle fibre lengths were so highly optimized that the fibres were

544 indeed able to operate close to the peak in their force-length curve across the whole range of digit

545 II motion. Little is known about the normal operating ranges of muscle fibres in non-mammalian

546 species during in vivo activity, but future experimental study of analogous extant animal systems

547 (e.g., pedal flexor muscles in birds of prey during prey grasping (Sustaita 2008)) can help

548 validate or refine assumptions made here.

549

550

551

552

553

554

555

556

557

558

559

560

561

562

563

564

565

566

567

\section{Implications for digit II and claw use}

The results obtained here provide new bearing on the validity of different proposed hypotheses of dromaeosaurid digit II and claw use (Table 2). Regardless of MTU input parameters and assumptions about MTU behaviour, it was consistently found that more crouched whole-limb postures lead to higher claw forces being produced. This favours behavioural hypotheses that involve more flexed limb angles (such as grasping or restraining small to large prey at close quarters; Fig. 1F), and detracts from hypotheses involving an outstretched or strongly extended limb (such as slash kicking very large prey at a distance; Fig. 1B,G). It is also consonant with the 'fighting dinosaurs' specimen, which purportedly shows life behaviours frozen in time (Barsbold 2016; Kielan-Jaworowska \& Barsbold 1972); the left hindlimb of the Velociraptor is striking its putative prey (the similarly-sized Protoceratops) in a non-extended leg posture, closest to posture 2 that was tested here (cf. Fig. 1E). The hypothesis of prey restraint in particular receives further support if muscle fibres were highly optimized to operate closer to the peak in their force-length curve (see above); here, claw force is maximized at flexed digit II postures, conducive to grasping and holding small prey. 
568 An additional result obtained here is an estimate of the magnitude of the maximum capable claw

569 force. In the initial set of assumptions of the system, the global maximum in claw force across the 570108 combinations tested was $18.9 \mathrm{~N}$ (Fig. 4A). This is a relatively small quantity, less than a

571 quarter of the flexor muscle force used to produce it in that particular combination $(82.0 \mathrm{~N})$. It is

572 also quite small $(<5 \%)$ in relation to the estimated body weight of the animal the model is based 573 upon (scaling by model femur length to the data of Turner et al. (2007), weight is estimated at

$574490 \mathrm{~N}$ ). This is in stark contrast to the forces applied in the physical model of Manning et al.

575 (2006), which equated to 2.5 times body weight. These comparisons do not change substantially

576 under other variations in model assumptions (Fig. 6). That claw force is relatively low is not

577 surprising, because the claw's large size produces a large ratio of out-lever to in-lever distances;

578 in the model, the distance from the claw tip to the second IP joint is 3.2-4.2 times the moment

579 arm of the flexor muscle about the joint. In life, the claw would have been sheathed in a

580 keratinous covering, extending the tip even further from the second IP joint and further reducing

581 the force produced at the tip. Larger forces would be achievable away from the claw tip nearer

582 the base (smaller out-lever arm), which would help improve the grasping of objects comparable

583 in size to, or smaller than, the radius of curvature of the claw (i.e., small prey). That only low

584 forces were achievable at the tip suggests that the claw by itself was probably not used to support 585 or transmit a large proportion of the animal's body weight into prey or other substrates (cf. Fig.

586 1C,D). However, body weight could still be used to help restrain prey (small or large) if

587 transmitted via the proximal toes and base of the metatarsus, such as by standing on top of the

588 prey animal (cf. Fig. 1F; Fowler et al. 2011). In addition, the claws could still aid in the

589 maintenance of position and balance by providing grip, for prey of any size.

590

591

592 Caveats

593

594 As in all modelling efforts, simplifying assumptions were made to facilitate more tractable analysis of the system. Possibly the most important is that only two muscles were modelled, yet it 596 is likely that digit II in dromaeosaurids was actuated by multiple flexor and extensor muscles, as

597 in extant archosaurs (Allen et al. 2015; Baumel et al. 1993; Cong 1998; George \& Berger 1966).

598 Moreover, the actions of multi-joint muscles, such as those modeled here, can be modulated by 
599 the actions of other muscles that actuate other parts of the limb (Kuo 2001); this would be

600 particularly pertinent for the 'long' variants of the muscles modeled here, which crossed both

601 knee and ankle joints. The movements of the IP and MTP joints were coupled in the present

602 study, but they may have been capable of some independent movement in life, requiring

603 additional muscles to actuate them. Another important caveat is that the model was analysed as a

604 static system only, yet dynamic effects may be important in life. These include muscle force-

605 velocity effects, tendon recoil and viscous effects from soft tissues that the claw is engaging.

606 Additionally, dynamic effects due to limb segment inertia and movement (especially that of the

607 proximal limb) could be quite important during high-velocity movements, at which point the

608 static assumption used here may become untenable. These assumptions can be tested and built

609 upon in the future, further refining interpretations of digit II function.

610

611

\section{Other theropods}

613

614

615

616

617

618

619

620

621

622

623

624

625

626

627

628
It is possible that the function of digit II and its claw may have varied among different dromaeosaurids. The characteristic morphology of digit II was present in phylogenetically basal (and much smaller) taxa that possessed markedly more elongate and gracile limbs than

Deinonychus (Turner et al. 2007). This may have resulted in a smaller relative change in length in the MTUs that actuated the digit, potentially influencing force production capabilities. At least one dromaeosaurid (Adasaurus) has an apomorphically reduced claw, yet it retains the characteristic ginglymoid and hyperextensible articular surface morphologies of the penultimate phalanges (Turner et al. 2012). Outside dromaeosaurids, the digit II claw of the troodontid Borogovia has reduced curvature, comparable to the relatively straight claws of the other pedal digits, with an apparently reduced capacity for interphalangeal flexion-extension (Osmólska 1987). Although beyond the scope of this study, modelling of other taxa can help assess if digit II was functionally conserved across dromaeosaurids and troodontids. More broadly, other clades of carnivorous non-avian theropod also developed hypertrophied claws, such as megaraptorans (Hocknull et al. 2009) and spinosaurids (Charig \& Milner 1986), although in these cases it is the claw of manual digit I. Musculoskeletal modelling of the forelimb of these taxa can address the

Page $\mathbf{2 1}$ of $\mathbf{3 1}$ 
629 function of their claws, and may in turn shed light on why hypertrophied claws evolved on the 630 manus in these groups, but on the pes in dromaeosaurids and troodontids.

631

632

633

634

635

636

637

638

639

640

641

642

643

644

645

646

647

648

649

650

651

652

653

654

655

656

657

658

\section{Conclusion}

Musculoskeletal modelling, posed within an optimization framework, has provided new insight on the function of pedal digit II and its claw in dromaeosaurids, arguably one of the most enigmatic anatomies among non-avian theropod dinosaurs. Across a variety of soft tissue and postural combinations and assumptions, it was found that more crouched hindlimb postures consistently increased claw force production. Combined with the relatively small magnitude of claw force and considerations of lever mechanics, this lends support to the hypothesis that digit II was employed in the grasping or restraint of prey smaller than the predator (i.e., small to large body size sensu Fowler et al. $(2009,2011))$. Other behaviours that involve a semi-crouched hindlimb posture are also plausible, such as stabbing or cutting prey at close quarters. In contrast, hypotheses involving strongly extended limbs, or the transmission of a large proportion of body weight into a substrate principally via the claws, are not well supported here. These findings should nevertheless be viewed with circumspect caution, as variation in muscle parameters or assumptions about muscle behaviour can exert an important influence on model results. Importantly, modelling has identified which aspects of dromaeosaurid functional anatomy require further investigation to refine the interpretations made herein.

\section{Acknowledgements}

Special thanks to J. Scannella and J. Horner (Museum of the Rockies) for access to the fossil material used in this study, and to K. Ugrin and D. Van Why (Bozeman Deaconess Hospital) for performing the CT scanning. Thanks also to D. Saxby, C. Pizzolato, S. Hocknull, J. Hutchinson, C. Clemente, F. De Groote and A. Falisse for helpful discussion or for assistance with the methodology used here, as well as colleagues of the Structure and Motion Laboratory. The

Page $\mathbf{2 2}$ of $\mathbf{3 1}$

PeerJ reviewing PDF | (2019:05:38118:1:2:NEW 3 Jul 2019) 
659 constructive comments of D. Fowler, J. Hutchinson, C. Clemente and an anonymous reviewer on 660 earlier versions of the manuscript are also greatly appreciated.

661

662

\section{Data accessibility}

664

665 Copies of the computed tomographic scan data are held by the Museum of the Rockies and the 666 Queensland Museum, Brisbane. All OpenSim model files and MATLAB code used in the present 667 study are included in the Supplementary Material.

668

669

670

Funding

671

672 Supported by an Australian Government Research Training Program Scholarship (awarded by

673 Griffith University), and an ERC Horizon 2020 Advanced Investigator Grant (695517, awarded

674 to J. Hutchinson).

675

676

677

678 Competing interests

679

680 None.

681

682

683

684

685

686

687

688

689

690

691

692 


\section{$\underline{\text { References }}$}

Adams D. 1987. The bigger they are, the harder they fall: implications of ischial curvature in ceratopsian dinosaurs. In: Currie PJ, and Koster EH, editors. Fourth Symposium on Mesozoic Terrestrial Ecosystems. Drumheller: Tyrrell Museum of Palaeontology.

Allen V, Elsey RM, Jones N, Wright J, and Hutchinson JR. 2010. Functional specialization and ontogenetic scaling of limb anatomy in Alligator mississippiensis. Journal of Anatomy 216:423-445.

Allen V, Molnar J, Parker W, Pollard A, Nolan G, and Hutchinson JR. 2015. Comparative architectural properties of limb muscles in Crocodylidae and Alligatoridae and their relevance to divergent use of asymmetrical gaits in extant Crocodylia. Journal of Anatomy 225:569-582.

Andersson JAE, Gillis J, Horn G, Rawlings JB, and Diehl M. 2019. CasADi: a software framework for nonlinear optimization and optimal control. Mathematical Programming Computation 11:1-36.

Attene M, and Falcidieno B. 2006. ReMESH: An Interactive Environment to Edit and Repair Triangle Meshes. Proceedings of the Eighth International Conference on Shape Modeling and Applications. Matushima. p 271-276.

Barsbold R. 2016. "The Fighting Dinosaurs": The Position of Their Bodies before and after Death. Palaeontological Journal 50:1412-1417.

Bates KT, Benson RBJ, and Falkingham PL. 2012. A computational analysis of locomotor anatomy and body mass evolution in Allosauroidea (Dinosauria: Theropoda). Paleobiology 38:486-507.

Bates KT, and Falkingham PL. 2012. Estimating maximum bite performance in Tyrannosaurus rex using multibody dynamics. Biology Letters 8:660-664.

Bates KT, and Falkingham PL. 2018. The importance of muscle architecture in biomechanical reconstructions of extinct animals: a case study using Tyrannosaurus rex. Journal of Anatomy 233:625-635.

Bates KT, Manning PL, Margetts L, and Sellers WI. 2010. Sensitivity analysis in evolutionary robotic simulations of bipedal dinosaur running. Journal of Vertebrate Paleontology 30:458-466.

Bates KT, and Schachner ER. 2012. Disparity and convergence in bipedal archosaur locomotion. Journal of the Royal Society Interface 9:1339-1353.

Baumel JJ, King AS, Breazile JE, Evans HE, and Vanden Berge JC. 1993. Handbook of Avian Anatomy: Nomina Anatomica Avium. Cambridge: Nuttal Ornithological Club.

Bishop PJ, Hocknull SA, Clemente CJ, Hutchinson JR, Farke AA, Barrett RS, and Lloyd DG. 2018. Cancellous bone architecture and theropod dinosaur locomotion. Part III Inferring posture and locomotor biomechanics in extinct theropods, and its evolution on the line to birds. PeerJ 6:e5777.

Bryant HN, Russel AP, Laroiya R, and Powell GL. 1996. Claw Retraction and Protraction in the Carnivora: Skeletal Microvariation in the Phalanges of the Felidae. Journal of Morphology 229:289-308.

Carpenter K. 1998. Evidence of predatory behaviour by carnivorous dinosaurs. Gaia 15:135-144. Carrano MT, and Hutchinson JR. 2002. Pelvic and hindlimb musculature of Tyrannosaurus rex (Dinosauria: Theropoda). Journal of Morphology 253:207-228. 
Charig AJ, and Milner AC. 1986. Baryonyx, a remarkable new theropod dinosaur. Nature 324:359-361.

Colbert EH, and Russell DA. 1969. The Small Cretaceous Dinosaur Dromaeosaurus. American Museum Novitates 2380:1-49.

Cong L. 1998. The Gross Anatomy of Alligator sinensis Fauvel. Beijing: Beijing Science Press.

Csiki Z, Vremir M, Brusatte SL, and Norell MA. 2010. An aberrant island-dwelling theropod dinosaur from the Late Cretaceous of Romania. Proceedings of the National Academy of Sciences 107:15357-15361.

Currie PJ, and Peng J-H. 1993. A juvenile specimen of Saurornithoides mongoliensis from the Upper Cretaceous of northern China. Canadian Journal of Earth Sciences 30:2224-2230.

De Groote F, Kinney AL, Rao AV, and Fregly BJ. 2016. Evaluation of Direct Collocation Optimal Control Problem Formulations for Solving the Muscle Redundancy Problem. Annals of Biomedical Engineering 44:2922-2936.

Delp SL, Anderson FC, Arnold AS, Loan P, Habib A, John CT, Guendelman E, and Thelen DG. 2007. OpenSim: Open-Source Software to Create and Analyze Dynamic Simulations of Movement. IEEE Transactions of Biomedical Engineering 54:1940-1950.

Delp SL, Loan P, Hoy MG, Zajac FE, Topp EL, and Rosen JM. 1990. An Interactive GraphicsBased Model of the Lower Extremity to Study Orthopaedic Surgical Procedures. IEEE Transactions of Biomedical Engineering 37:757-767.

Einoder L, and Richardson A. 2006. An ecomorphological study of the raptorial digital tendon locking mechanism. Ibis 148:515-525.

Einoder L, and Richardson A. 2007. The digital tendon locking mechanism of owls: variation in the structure and arrangement of the mechanism and functional implications. Emu 107:223-230.

Fowler DW, Freedman EA, and Scannella JB. 2009. Predatory Functional Morphology in Raptors: Interdigital Variation in Talon Size Is Related to Prey Restraint and Immobilisation Technique. PLoS ONE 4:e7999.

Fowler DW, Freedman EA, Scannella JB, and Kambic RE. 2011. The Predatory Ecology of Deinonychus and the Origin of Flapping in Birds. PLOS ONE 6:e28964.

Garner BA, and Pandy MG. 2000. The Obstacle-Set Method for Representing Muscle Paths in Musculoskeletal Models. Computer Methods in Biomechanics and Biomedica Engineering 3:1-30.

George JC, and Berger AJ. 1966. Avian Myology. New York: Academic Press.

Gignac PM, Makovicky PJ, Erickson GM, and Walsh RP. 2010. A description of Deinonychus antirrhopus bite marks and estimate of bite force using tooth indentation simulations. Journal of Vertebrate Paleontology 30:1169-1177.

Gishlick AD. 2001. The function of the manus and forelimb of Deinonychus antirrhopus and its importance for the origin of avian flight. In: Gauthier JA, and Gall JF, eds. New Perspectives on the Origin and Early Evolution of Birds. New Haven: Peabody Museum of Natural History, Yale University, 301-318.

Godefroit P, Cau A, Dong-Yu H, Escuillié F, Wenhao W, and Dyke G. 2013. A Jurassic avialan dinosaur from China resolves the early phylogenetic history of birds. Nature 498:359362.

Gonyea W, and Ashworth R. 1975. The Form and Function of Retractile Claws in the Felidae and Other Representative Carnivorans. Journal of Morphology 145:229-238. 
Henderson DM. 2012. Engineering a Dinosaur. In: Brett-Surman MK, Holtz TR, Jr, and Farlow JO, eds. The Complete Dinosaur. 2 ed. Bloomington: Indiana University Press, 637-666. Hocknull SA, White MA, Tischler TR, Cook AG, Calleja ND, Sloan T, and Elliott DA. 2009. New Mid-Cretaceous (Latest Albian) Dinosaurs from Winton, Queensland, Australia. PLoS ONE 4:e6190.

Hutchinson JR. 2002. The evolution of hindlimb tendons and muscles on the line to crown-group birds. Comparative Biochemistry and Physiology, Part A 133:1051-1086.

Hutchinson JR. 2004a. Biomechanical Modeling and Sensitivity Analysis of Bipedal Running Ability. I. Extant Taxa. Journal of Morphology 262:421-440.

Hutchinson JR. 2004b. Biomechanical Modeling and Sensitivity Analysis of Bipedal Running Ability. II. Extinct Taxa. Journal of Morphology 262:441-461.

Hutchinson JR, Anderson FC, Blemker SS, and Delp SL. 2005. Analysis of hindlimb muscle moment arms in Tyrannosaurus rex using a three-dimensional musculoskeletal computer model: implications for stance, gait, and speed. Paleobiology 31:676-701.

Hutchinson JR, Miller CE, Fritsch G, and Hildebrandt T. 2008. The Anatomical Foundation for Multidisciplinary Studies of Animal Limb Function: Examples from Dinosaur and Elephant Limb Imaging Studies. In: Endo H, and Frey R, eds. Anatomical Imaging: Towards a New Morphology. Tokyo: Springer, 23-38.

Hutchinson JR, Ng-Thow-Hing V, and Anderson FC. 2007. A 3D interactive method for estimating body segmental parameters in animals: Application to the turning and running performance of Tyrannosaurus rex. Journal of Theoretical Biology 246:660-6800.

Hutchinson JR, Rankin JW, Rubenson J, Rosenbluth KH, Siston RA, and Delp SL. 2015. Musculoskeletal Modelling of an ostrich (Stuthio camelus) pelvic limb: influence of limb orientation of muscular capacity during locomotion. PeerJ 3:e1001.

Kielan-Jaworowska Z, and Barsbold R. 1972. Narrative of the Polish-Mongolian Palaeontological Expeditions 1967-1971. Palaeontologica Polonica 27:5-13.

Kuo AD. 2001. The Action of Two-Joint Muscles: The Legacy of W. P. Lombard. In: Latash ML, and Zatsiorsky VM, eds. Classics in Movement Science. Champaign: Human Kinetics, 289-315.

Lamas LP, Main RP, and Hutchinson JR. 2014. Ontogenetic scaling patterns and functional anatomy of the pelvic limb musculature in emus (Dromaius novaehollandiae). PeerJ 2:e716.

Lautenschlager S, Brassey CA, Button DJ, and Barrett PM. 2016. Decoupled form and function in disparate herbivorous dinosaur clades. Scientific Reports 6:26495.

Li R, Lockley MG, Makovicky PJ, Matsukawa M, Norell MA, Harris JD, and Liu M. 2008. Behavioural and faunal implications of Early Cretaceous deinonychosaur trackways from China. Naturwissenschaften 95:185-191.

Lockley MG, Harris JD, Li R, Xing L, and van der Lubbe T. 2016. Two-Toed Tracks through Time: On the Trail of "Raptors" and Their Allies. In: Falkingham PL, Marty D, and Richter A, eds. Dinosaur Tracks: The Next Steps. Bloomington: Indiana University Press, 183-200.

Maidment SCR, Bates KT, Falkingham PL, VanBuren C, Arbour V, and Barrett PM. 2014. Locomotion in ornithischian dinosaurs: an assessment using three-dimensional computational modelling. Biological Reviews 89:588-617.

Manning PL, Margetts L, Johnson MR, Withers PJ, Sellers WI, Falkingham PL, Mummery PM, Barrett PM, and Raymont DR. 2009. Biomechanics of Dromaeosaurid Dinosaur Claws: 
Application of X-Ray Microtomography, Nanoindentation, and Finite Element Analysis. The Anatomical Record 292:1397-1405.

Manning PL, Payne D, Pennicott J, Barrett PM, and Ennos RA. 2006. Dinosaur killer claws or climbing crampons? Biology Letters 2:110-112.

Martelli S, Taddei F, Testi D, Delp SL, and Viceconti M. 2011. NMSBuilder: an application to personalize NMS models. Proceedings of the 23rd Congress of the International Society of Biomechanics. Brussels.

Mateo S, Revol P, Fourtassi M, Rossetti Y, Collet C, and Rode G. 2013. Kinematic characteristics of tenodesis grasp in C6 quadriplegia. Spinal Cord 51:144-149.

McMahon TA. 1984. Muscles, Reflexes, and Locomotion. Princeton: Princeton University Press.

Millard M, Uchida T, Seth A, and Delp SL. 2013. Flexing Computational Muscle: Modeling and Simulation of Musculotendon Dynamics. Journal of Biomechanical Engineering 135:021004.

Nagano A, Umberger BR, Marzke MW, and Gerritsen KGM. 2005. Neuromusculoskeletal Computer Modeling and Simulation of Upright, Straight-Legged, Bipedal Locomotion of Australopithecus afarensis (A.L. 288-1). American Journal of Physical Anthropology 126:2-13.

Norell MA, and Makovicky PJ. 1997. Important Features of the Dromaeosaur Skeleton: Information from a New Specimen. American Museum Novitates 3215:1-28.

Norell MA, and Makovicky PJ. 2004. Dromaeosauridae. In: Weishampel DB, Dodson P, and Osmólska H, eds. The Dinosauria. 2 ed. Berkeley: University of California Press.

Osmólska H. 1987. Borogovia gracilicrus gen. et sp. n., a new troodontid dinosaur from the Late Cretaceous of Mongolia. Acta Palaeontologica Polonica 32:133-150.

Ostrom JH. 1969a. A new theropod dinosaur from the Lower Cretaceous of Montana. Postilla 128:1-17.

Ostrom JH. 1969b. Osteology of Deinonychus antirrhopus, and unusual theropod from the Lower Cretaceous of Montana. Bulletin of the Peabody Museum of Natural History 30:1165.

Ostrom JH. 1976. On a New Specimen of the Lower Cretaceous Theropod Dinosaur Deinonychus antirrhopus. Breviora 439:1-21.

Ostrom JH. 1990. Dromaeosauridae. In: Weishampel DB, Dodson P, and Osmólska H, eds. The Dinosauria. Berkeley: University of California Press, 269-279.

Ostrom JH. 1994. Deinonychus, The Ultimate Killing Machine. In: Rosenberg GD, and Wolberg DL, editors. DINO FEST, a Conference for the General Public: The Paleontological Society. p 127-137.

Pagel M. 1991. Constructing 'everyanimal'. Nature 351:532-533.

Paul GS. 1988. Predatory Dinosaurs of the World. New York: Simon \& Schuster.

Paxton H, Anthony NB, Corr SA, and Hutchinson JR. 2010. The effects of selective breeding on the architectural properties of the pelvic limb in broiler chickens: a comparative study across modern and ancestral populations. Journal of Anatomy 217:153-166.

Quinn TH, and Baumel JJ. 1990. The digital tendon locking mechanism of the avian foot (Aves). Zoomorphology 109:281-293.

Rankin JW, Rubenson J, and Hutchinson JR. 2016. Inferring muscle functional roles of the ostrich pelvic limb during walking and running using computer optimizaion. Journal of the Royal Society Interface 13:20160035. 
Reinschmidt C, and van den Bogert T. 1997. KineMat: a MATLAB Toolbox for ThreeDimensional Kinematic Analyses. Calgary: Human Performance Laboratory.

Sellers WI, Margetts L, Coria RA, and Manning PL. 2013. March of the Titans: The Locomotor Capabilities of Sauropod Dinosaurs. PLoS ONE 8:e78733.

Sellers WI, Pond SB, Brassey CA, Manning PL, and Bates KT. 2017. Investigating the running abilities of Tyrannosaurus rex using stress-constrained multibody dynamic analysis. PeerJ 5:e3420.

Senter P. 2009. Pedal function in deinonychosaurs (Dinosauria: Theropoda): a comparative study. Bulletin of the Gunma Museum of Natural History 13:1-14.

Simpson EL, Hilbert-Wolf HL, Wizevich MC, Tindall SE, Fasinski BR, Storm LP, and Needle MD. 2010. Predatory digging behaviour by dinosaurs. Geology 38:699-702.

Smith NC, Wilson AM, Jespers KJ, and Payne RC. 2006. Muscle architecture and functional anatomy of the pelvic limb of the ostrich (Struthio camelus). Journal of Anatomy 209:765-779.

Spoor CW, and Veldpaus FE. 1980. Rigid body motion calculated from spatial coordinates of markers. Journal of Biomechanics 13:391-393.

Sustaita D. 2008. Musculoskeletal Underpinnings to Differences in Killing Behaviour Between North American Accipiters (Falconiformes: Accipitridae) and Falcons (Falconidae). Journal of Morphology 269:283-301.

Turner AH, Makovicky PJ, and Norell MA. 2012. A review of dromaeosaurid systematics and paravian phylogeny. Bulletin of the American Museum of Natural History 371:1-206.

Turner AH, Pol D, Clarke JA, Erickson GM, and Norell MA. 2007. A Basal Dromaeosaurid and Size Evolution Preceding Avian Flight. Science 317:1378-1381.

Valente G, Pitto L, Testi D, Seth A, Delp SL, Stagni R, Viceconti M, and Taddei F. 2014. Are Subject-Specific Musculoskeletal Models Robust to the Uncertainties in Parameter Identification? PLOS ONE 9:e112625.

Witmer LM. 1995. The extant phylogenetic bracket and the importance of reconstructing soft tissues in fossils. In: Thomason JJ, ed. Functional Morphology in Vertebrate Paleontology. Cambridge: Cambridge University Press, 19-33.

Xing L, Lockley MG, Guo Y, Klein H, Zhang J, Zhang L, Persons WS, IV, Romilio A, Tang Y, and Wang X. 2018. Multiple parallel deinonychosaurian trackways from a diverse dinosaur track assemblage of the Lower Cretaceous Dasheng Group of Shandong Province, China. Cretaceous Research 90:40-55.

Xing L, Lockley MG, Yang G, Xu X, Cao J, Klein H, Persons WS, IV, Shen H-J, and Zheng XM. 2015. Unusual deinonychosaurian track morphology (Velociraptorichnus zhangi $\mathrm{n}$. ichnosp.) from the Lower Cretaceous Xiaoba Formation, Sichuan Province, China. Palaeoworld 24:283-292.

Xu X, Zhou Z, Wang X, Kuang X, Zhang F, and Du X. 2003. Four-winged dinosaurs from China. Nature 421:335-340.

Zajac FE. 1989. Muscle and tendon: properties, models, scaling, and application to biomechanics and motor control. Critical Reviews in Biomedical Engineering 17:359-410. 


\section{Figure captions}

919

920 Figure 1. The famed 'sickle claw' of pedal digit II in dromaeosaurids and its hypothesized uses.

921 (A) Schematic illustration of the left pes of Deinonychus (after Ostrom (1969b)), which also

922 illustrates the widespread inference that digit II was retracted off the ground when the claw was

923 not in use. (B-H) Various hypotheses previously proposed for how the claw was used in life. (B)

924 Kicking or slashing of prey. (C) Used for gripping onto the flanks of struggling prey. (D) Using

925 body weight to drive the claws down the side of the prey's flank. (E) Piercing or slashing specific

926 vital areas of the prey. (F) Pinning down and immobilizing prey to be dispatched by the mouth

927 and forelimbs. (G) Intra- or interspecific defence. (H) Digging out prey from nests or burrows.

928 The schematics in B-H are based as closely as possible on the original descriptions (and

929 sometimes illustrations) of the hypothesized behaviours in the literature; see main text for

930 citations. Also note that integument (e.g., feathers) is omitted for clarity.

931

932

933

Figure 2. Mathematical representation of muscle architecture and its force-length-velocity

934

relationships. (A) At the organ level, muscle is typically represented with a Hill-type

935 computational model, which comprises a contractile element (CE) in parallel with a passive

936 elastic element (PEE), which are in turn in series with a second elastic element (SEE)

937 representing the tendon; see Zajac (1989) and Millard et al. (2013) for more detail. This model

938 factors in the architectural parameters of optimum fibre length $\left(\ell_{0}\right)$, pennation angle at optimum

939 fibre length $\left(\alpha_{\mathrm{o}}\right)$ and tendon slack length $\left(L_{\mathrm{s}}\right)$. (B-D) The relationships between normalized force

940 ( $F^{*}$, equal to force divided by maximum isometric force), normalized fibre length ( $\ell^{*}$, equal to

941 fibre length divided by $\ell_{\mathrm{o}}$ ) or normalized tendon length ( $L^{*}$, equal to tendon length divided by $\left.L_{\mathrm{s}}\right)$

942 and normalized fibre velocity ( $v^{*}$, equal to fibre velocity divided by maximum contraction

943 velocity). (B) Force-length relationships of the active (red) and passive (blue) muscle

944 components. (C) Force-length relationship of tendon. (D) Force-velocity relationship of the

945 active muscle component; in the current study this is ignored as all analyses are static only. The curves in B-D are based on the formulation of De Groote et al. (2016). 
949 Figure 3. Musculoskeletal model of the right hindlimb of Deinonychus used in the study. (A) The 950 full model in medial (left) and anterior (right) view, showing the wrapping surfaces (blue) used to 951 help constrain MTU paths (red). (B) Three whole-limb postures were tested for, spanning from 952 extended (1) to crouched (3) configurations. (C) Two different lengths of each MTU were tested 953 for, short MTUs originating from the proximal tibia (left) and long MTUs originating from the 954 distal femur (right). (D) The motion of the MTP joint (and the two IP joints that were 955 programmatically coupled to it) ranged from $-65^{\circ}$ of flexion through to $60^{\circ}$ of extension. Arrows 956 show the points at which MTU length distal to the ankle was measured, used in the calculation of bounds to tendon slack length (see Table 1). For scale, the femur in the model is $291 \mathrm{~mm}$ long.

Figure 4. Optimization results for the initial system configuration, showing claw force $\left(F_{\text {claw }}\right)$ plotted against metatarsophalangeal joint angle $\left(\theta_{\mathrm{MTP}}\right)$. (A) Results for the 108 combinations of posture, muscle volume and muscle length, parsed by posture. (B) Results for claw force for one of the 108 combinations include 126 force-angle curves calculated for the optimal musculotendon parameters identified for each degree of the range of $\theta_{\mathrm{MTP}}$; the maximal envelope

965 of these curves (dotted line) contributes data to panel A (arrow). (C-F) Results for the 108 966 combinations parsed by flexor muscle volume (C), extensor muscle volume (D), flexor muscle length (E) and extensor muscle length (F). In A, C-F, curves show the mean values, shaded 968 regions denote total range, and crosses denote maxima for each of the 108 curves that are represented in the plots.

972 Figure 5. Optimal values of musculotendon parameters for the initial system configuration, 973 plotted against metatarsophalangeal joint angle $\left(\theta_{\text {MTP }}\right)$ and parsed by posture. (A, B) Optimal 974 fibre length. (C, D) Tendon slack length. (E, F) Pennation angle. Panels A, C and E are for the 975 flexor muscle; panels B, D and F are for the extensor muscle. Black dashed lines denote 976 minimum, maximum and mean curves across all combinations. 
979 Figure 6. Optimization results for the four sensitivity analyses, showing claw force $\left(F_{\text {claw }}\right)$ plotted 980 against metatarsophalangeal joint angle $\left(\theta_{\mathrm{MTP}}\right)$. (A) More constrained operating range for muscle 981 fibres. (B) Extensor muscle actively contracting in holding digit II off the ground. (C) Muscle 982 strength is doubled. (D) More restrictive bounds on the allowable range of pennation angles in 983 the optimization. All results are parsed by posture. Curves show the mean values, shaded regions 984 denote total range, and crosses denote maxima for each of the 108 curves that are represented in 985 the plots. 


\section{Figure 1 (on next page)}

The famed 'sickle claw' of pedal digit II in dromaeosaurids and itshypothesized uses.

(A) Schematic illustration of the left pes of Deinonychus (after Ostrom (1969b), which also illustrates the widespread inference that digit II was retracted off the ground when the claw was not in use. (B-H) Various hypotheses previously proposed for how the claw was used in life. (B) Kicking or slashing of prey. (C) Used for gripping onto the flanks of struggling prey. (D) Using body weight to drive the claws down the side of the prey's flank. (E) Piercing or slashing specific vital areas of the prey. (F) Pinning down and immobilizing prey to be dispatched by the mouth and forelimbs. (G) Intra- or interspecific defence. (H) Digging out prey from nests or burrows. The schematics in $\mathrm{B}-\mathrm{H}$ are based as closely as possible on the original descriptions (and sometimes illustrations) of the hypothesized behaviours in the literature; see main text for citations. Also note that integument (e.g., feathers) is omitted for clarity. 


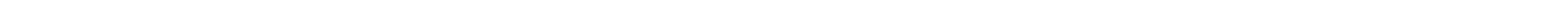

E

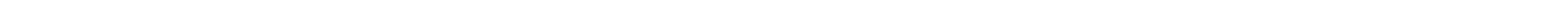

B

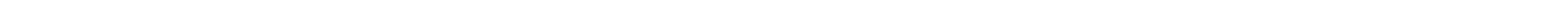

Manuscript to be refrewed

F

H
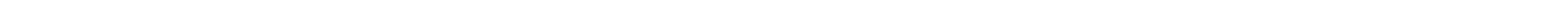


\section{Figure 2 (on next page)}

Mathematical representation of muscle architecture and itsforce-length-velocity relationships.

(A) At the organ level, muscle is typically represented with a Hill-type computational model, which comprises a contractile element (CE) in parallel with a passive elastic element (PEE), which are in turn in series with a second elastic element (SEE) representing the tendon; see Zajac (1989) and Millard et al. (2013) for more detail. This model factors in the architectural parameters of optimum fibre length $\left(\ell_{0}\right)$, pennation angle at optimum fibre length $\left(\alpha_{0}\right)$ and tendon slack length $\left(L_{s}\right)$. (B-D) The relationships between normalized force $\left(F^{*}\right.$, equal to force divided by maximum isometric force), normalized fibre length ( $\ell^{*}$, equal to fibre length divided by $\left.\ell_{0}\right)$ or normalized tendon length $\left(L *\right.$, equal to tendon length divided by $\left.L_{s}\right)$ and normalized fibre velocity ( $v^{*}$, equal to fibre velocity divided by maximum contraction velocity). (B) Force-length relationships of the active (red) and passive (blue) muscle components. (C) Force-length relationship of tendon. (D) Force-velocity relationship of the active muscle component; in the current study this is ignored as all analyses are static only. The curves in B-D are based on the formulation of De Groote et al. (2016) . 


\section{Figure 3}

Musculoskeletal model of the right hindlimb of Deinonychus used in the study.

(A) The full model in medial (left) and anterior (right) view, showing the wrapping surfaces

(blue) used to help constrain MTU paths (red). (B) Three whole-limb postures were tested for, spanning from extended (1) to crouched (3) configurations. (C) Two different lengths of each MTU were tested for, short MTUs originating from the proximal tibia (left) and long MTUs originating from the distal femur (right). (D) The motion of the MTP joint (and the two IP joints that were programmatically coupled to it) ranged from $-65^{\circ}$ of flexion through to $60^{\circ}$ of extension. Arrows show the points at which MTU length distal to the ankle was measured, used in the calculation of bounds to tendon slack length (see Table 1). For scale, the femur in the model is $291 \mathrm{~mm}$ long. 


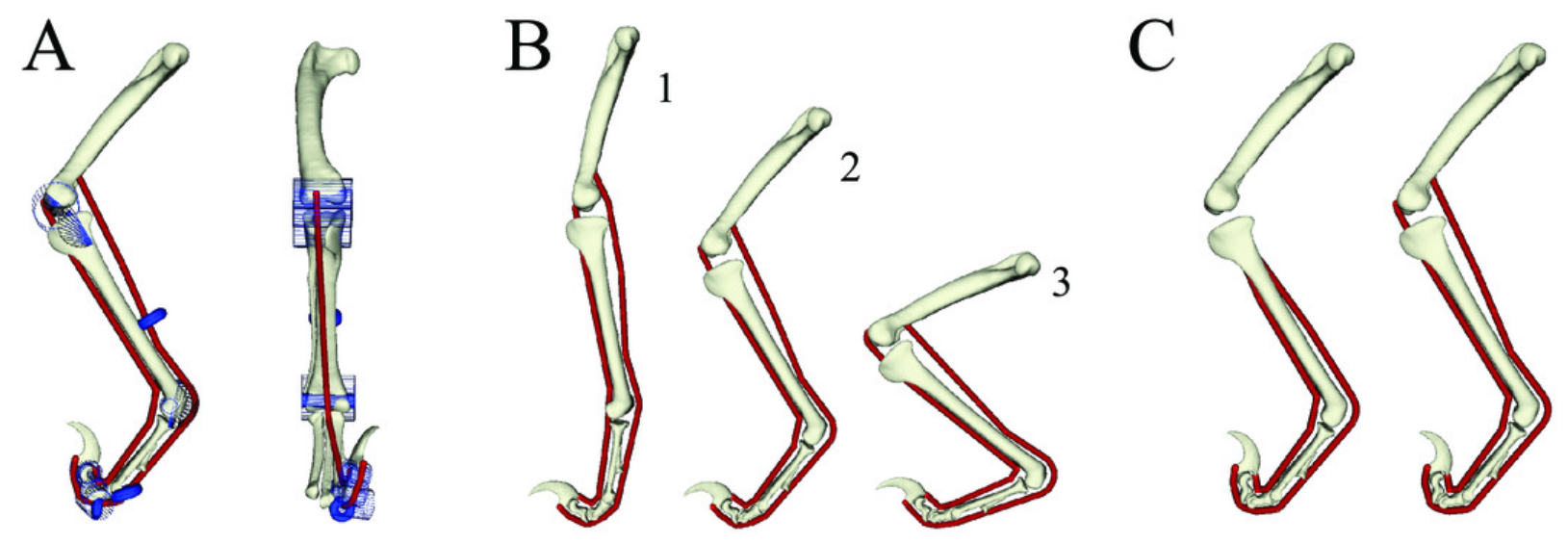

D

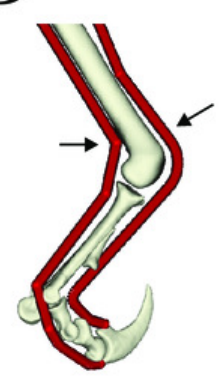

$-65^{\circ}$
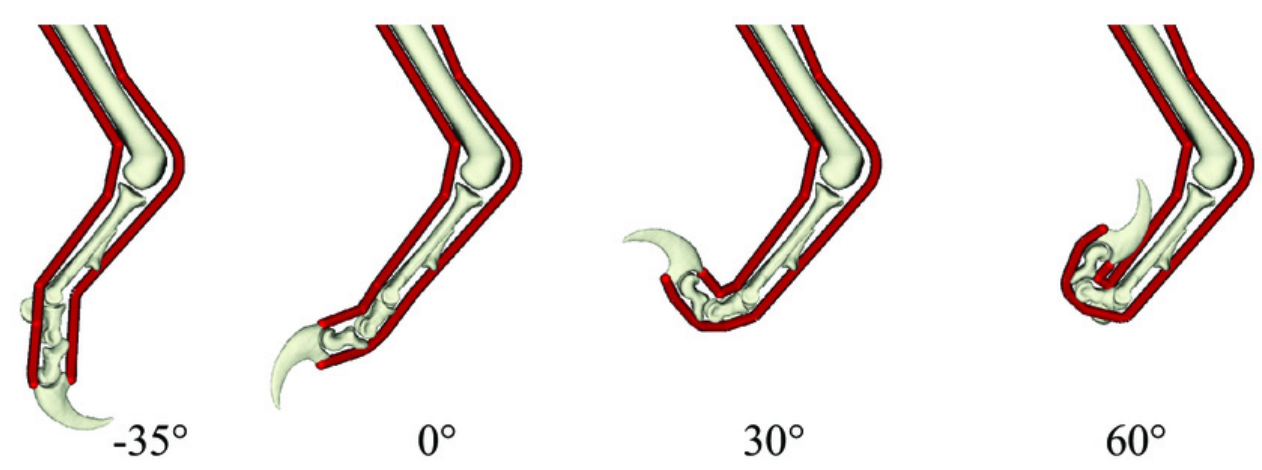

PeerJ reviewing PDF | (2019:05:38118:1:2:NEW 3 Jul 2019) 


\section{Figure 4 (on next page)}

Optimization results for the initial system configuration, showing clawforce $\left(F_{\text {claw }}\right)$ plottedagainst metatarsophalangeal joint angle $\left(\theta_{\text {мтP }}\right)$.

(A) Results for the 108 combinations of posture, muscle volume and muscle length, parsed by posture. (B) Results for claw force for one of the 108 combinations include 126 force-angle curves calculated for the optimal musculotendon parameters identified for each degree of the range of $\theta_{\text {Мтр }}$; the maximal envelope of these curves (dotted line) contributes data to panel A (arrow). (C-F) Results for the 108 combinations parsed by flexor muscle volume (C), extensor muscle volume (D), flexor muscle length (E) and extensor muscle length (F). In A, C-F, curves show the mean values, shaded regions denote total range, and crosses denote maxima for each of the 108 curves that are represented in the plots. 
A

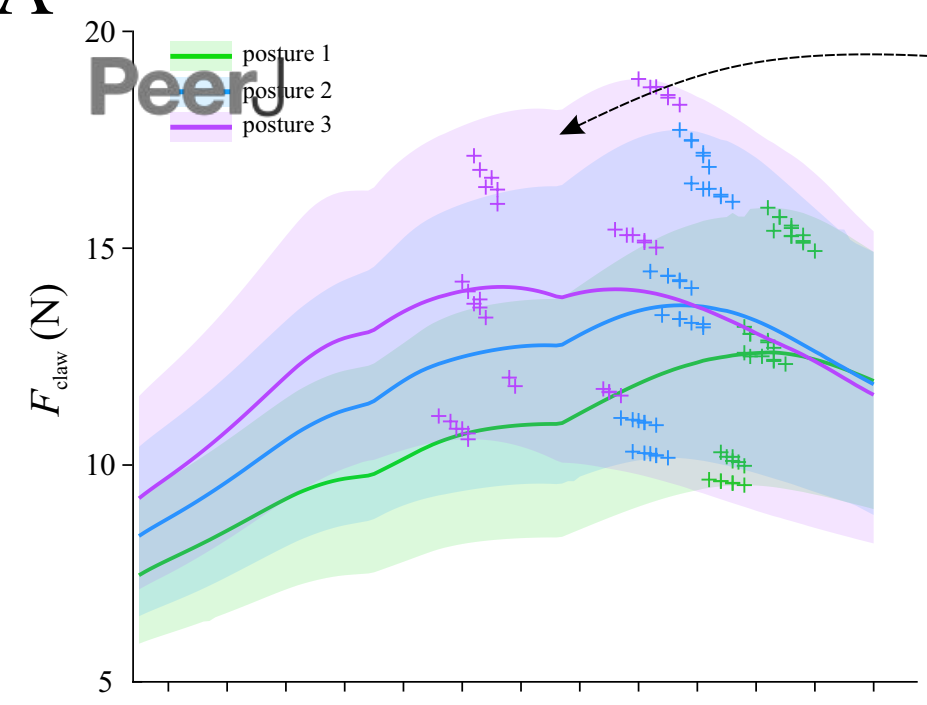

C

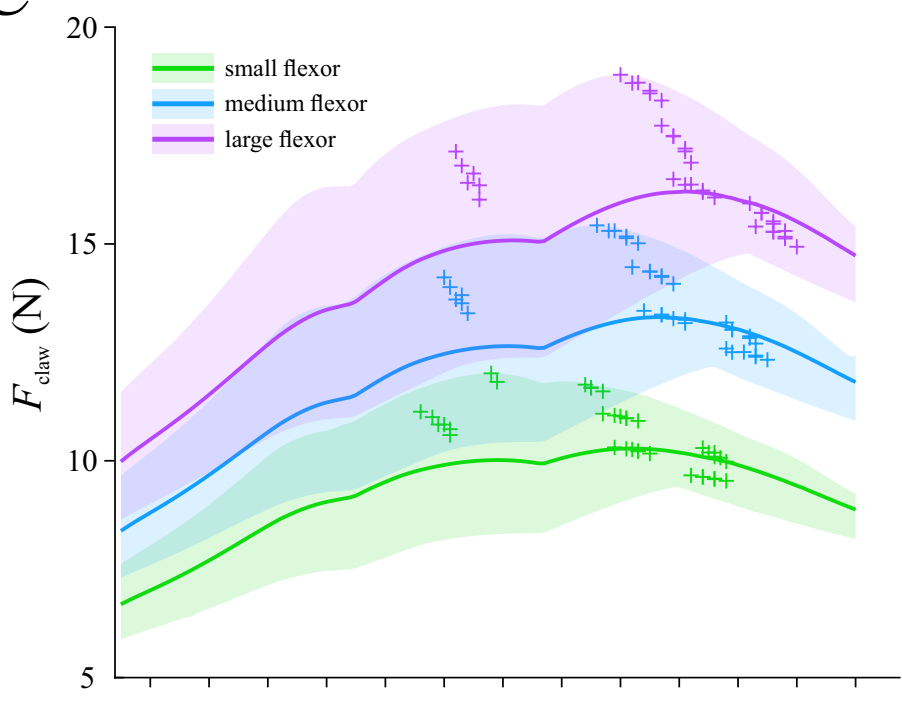

E

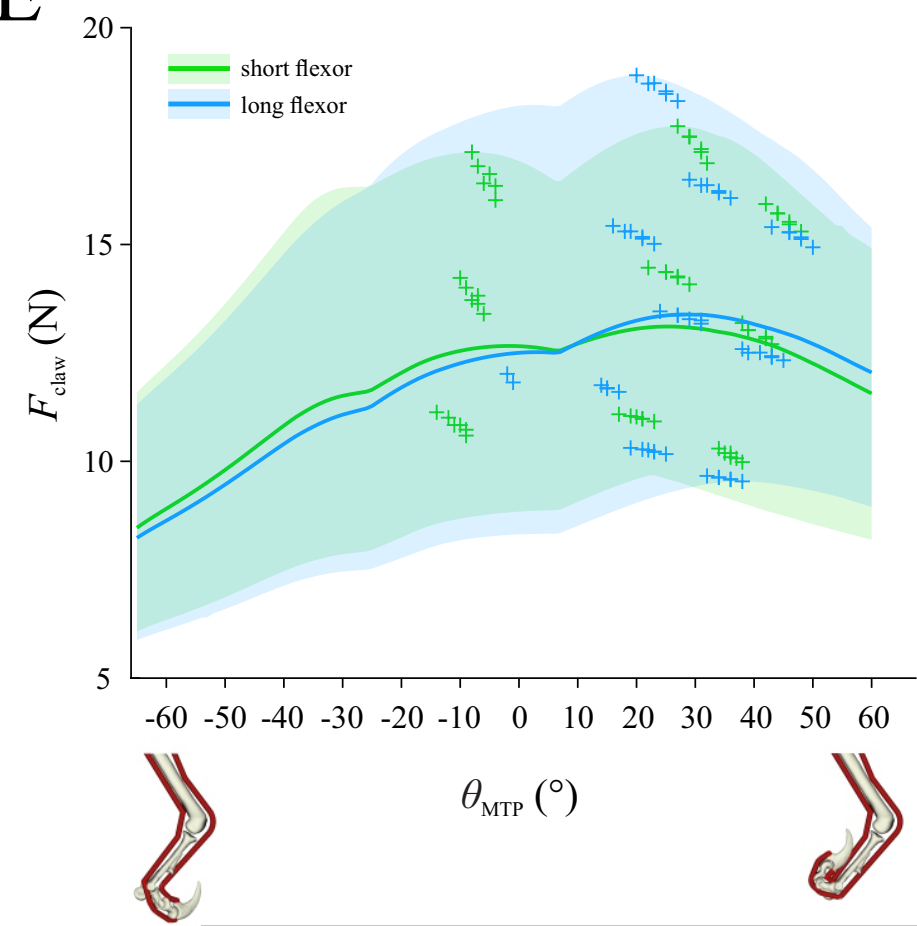

PeerJ reviewing PDF | (2019:05:38118:1:2:NEW 3 Jul 2019)
B

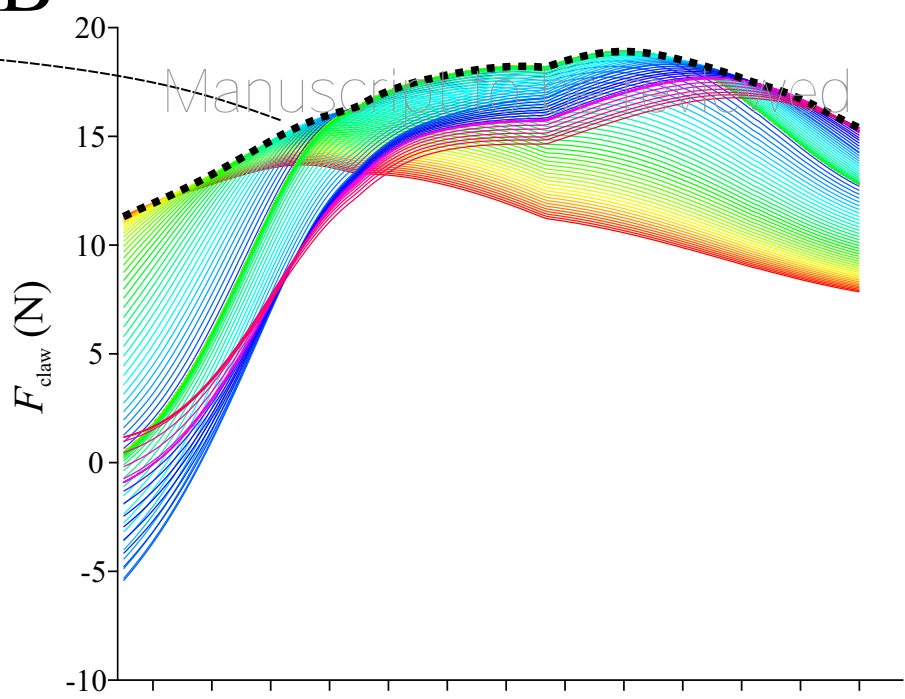

D

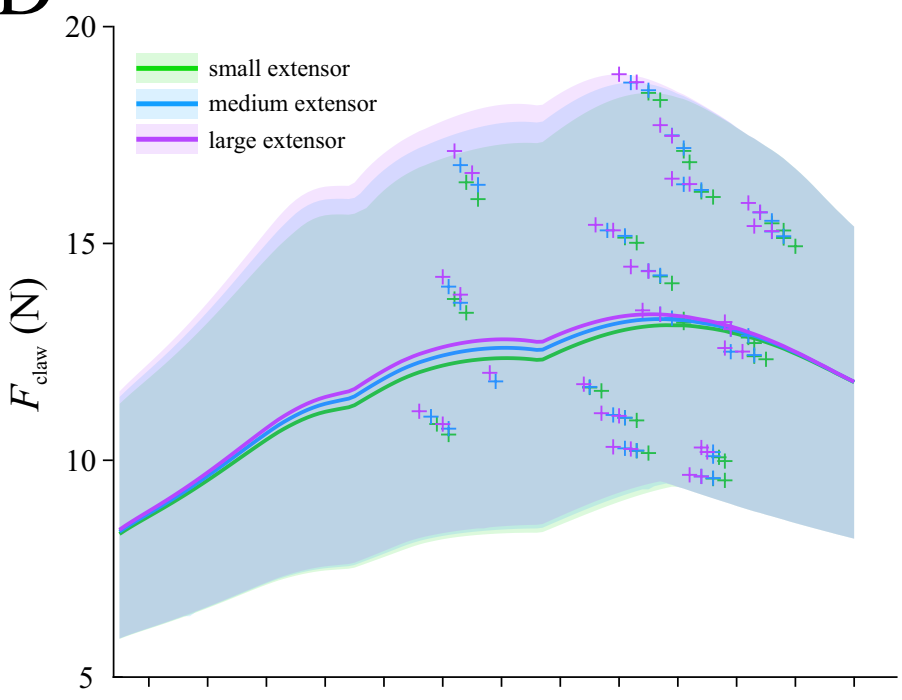

F

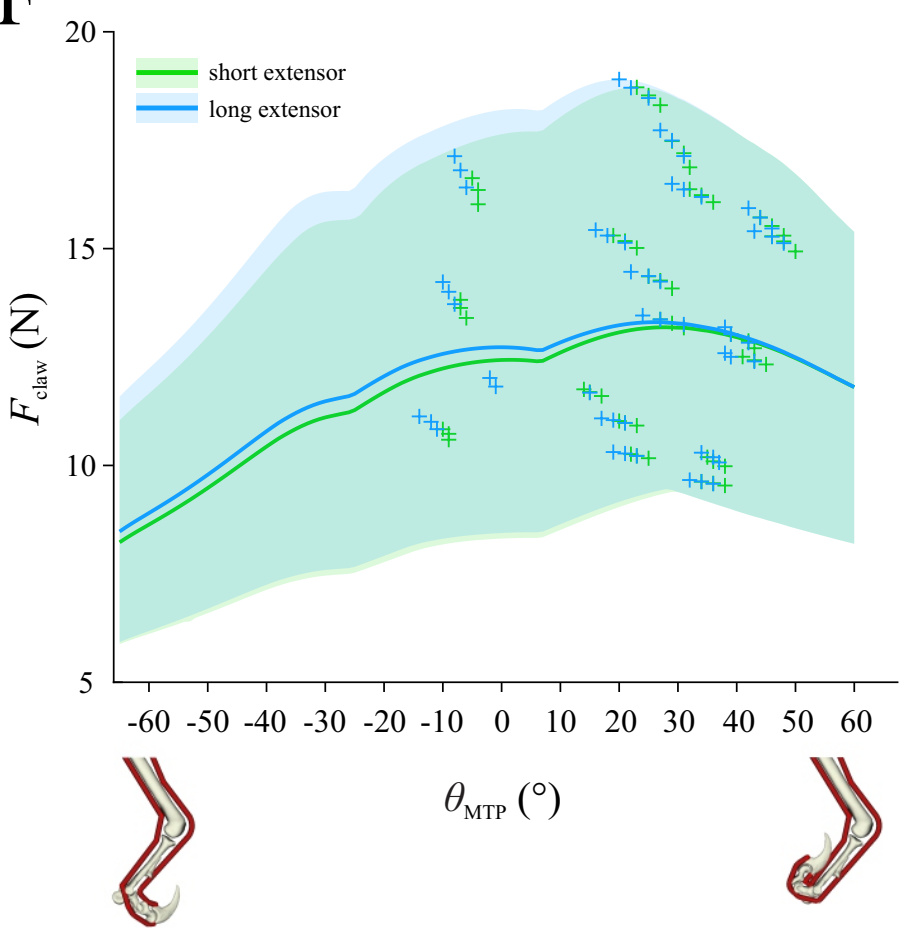


Figure $\mathbf{5}$ (on next page)

Optimal values of musculotendon parameters for the initial systemconfiguration, plotted against metatarsophalangeal joint angle ( $\theta_{\text {мтP }}$ ) and parsed by posture.

(A, B) Optimal fibre length. (C, D) Tendon slack length. (E, F) Pennation angle. Panels A, C and $\mathrm{E}$ are for the flexor muscle; panels $\mathrm{B}, \mathrm{D}$ and $\mathrm{F}$ are for the extensor muscle. Black dashed lines denote minimum, maximum and mean curves across all combinations. 
A

flexor

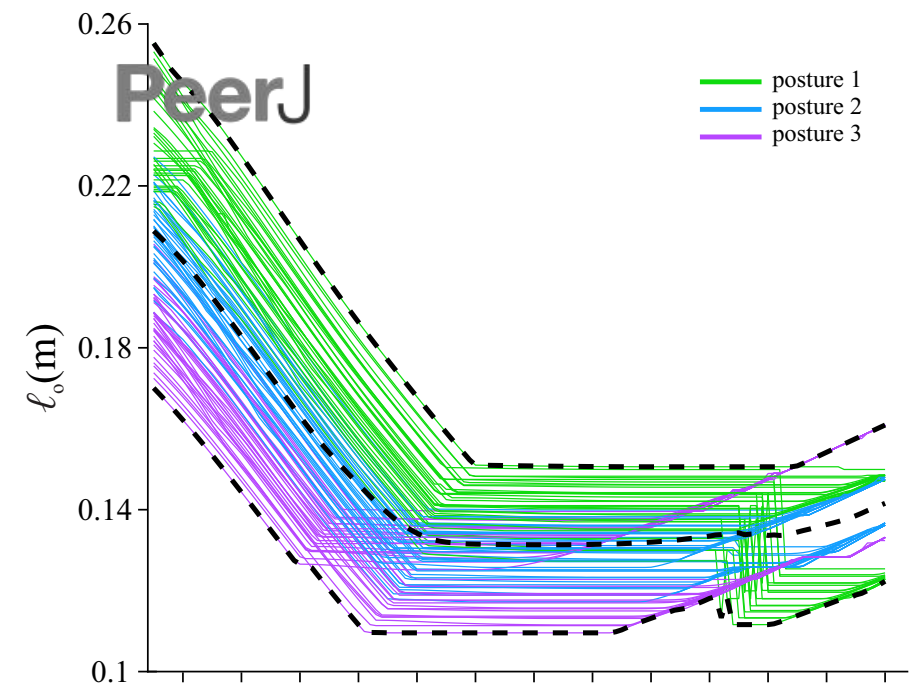

C

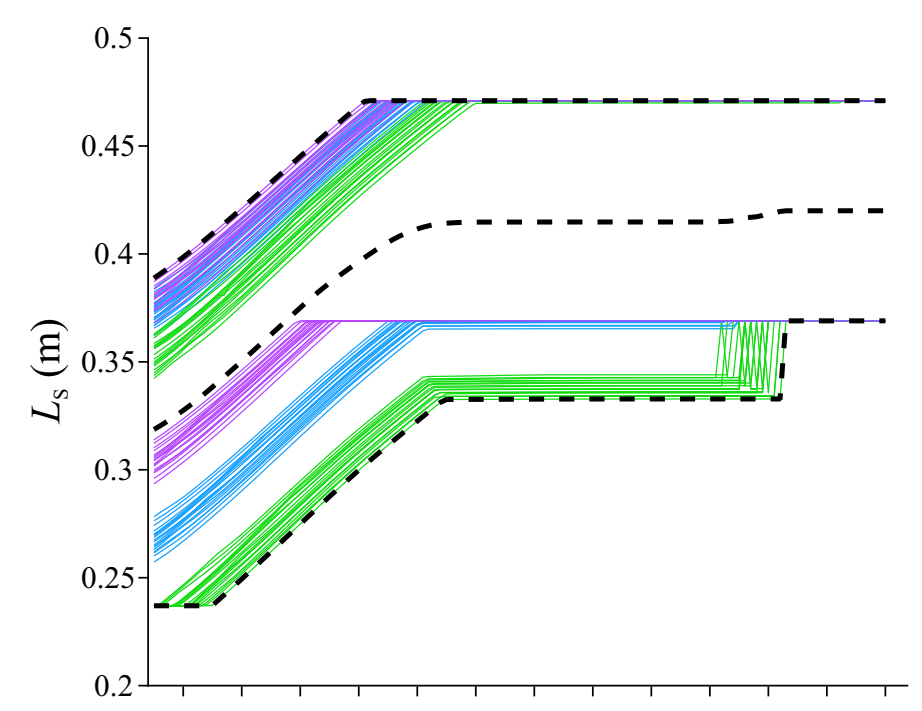

E

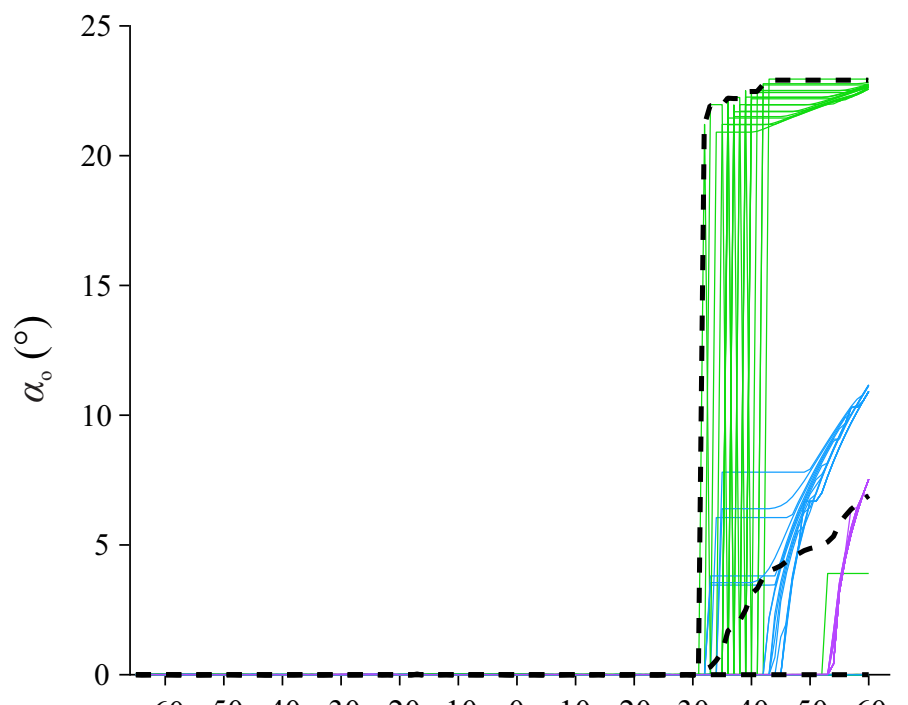

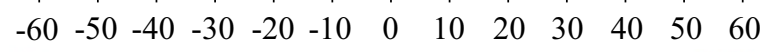

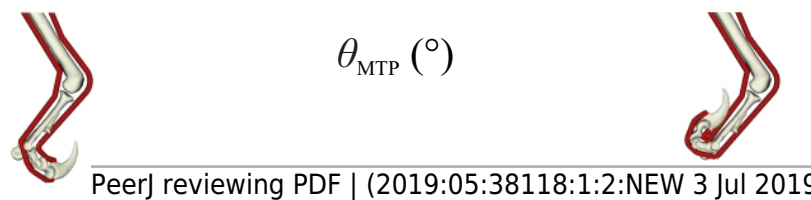

B

extensor

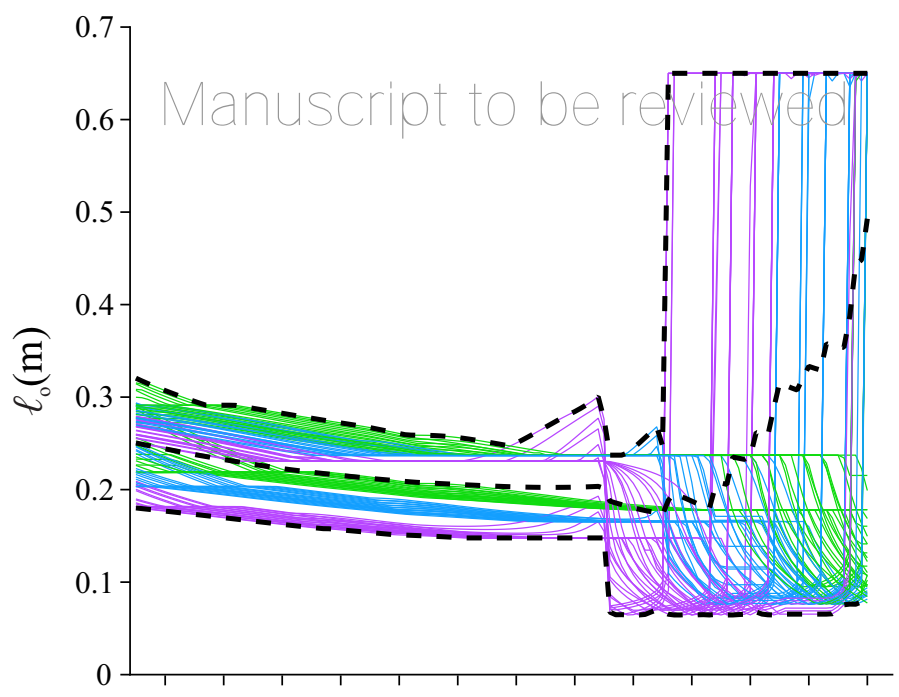

D

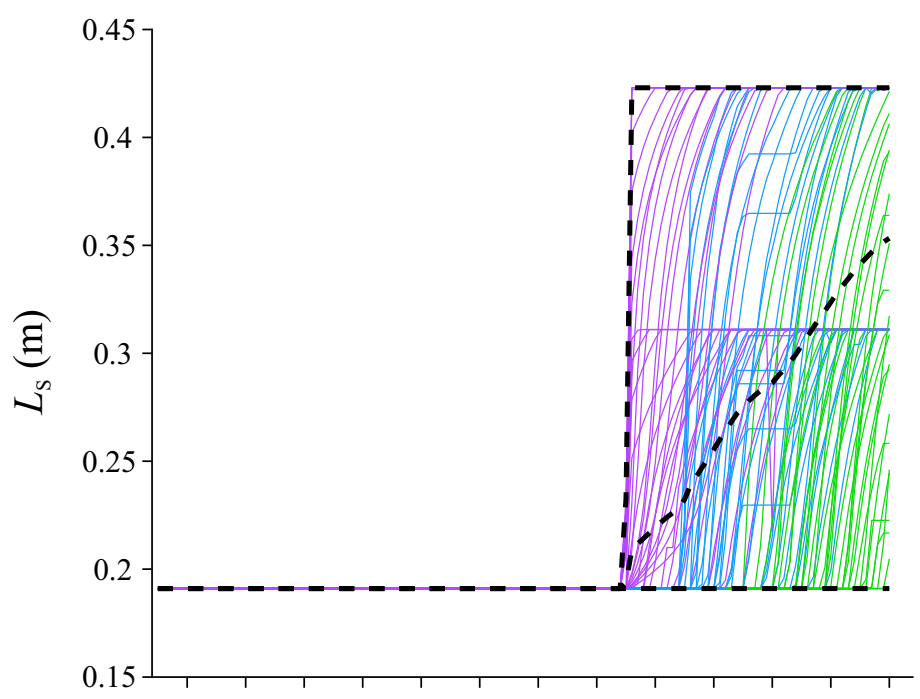

F
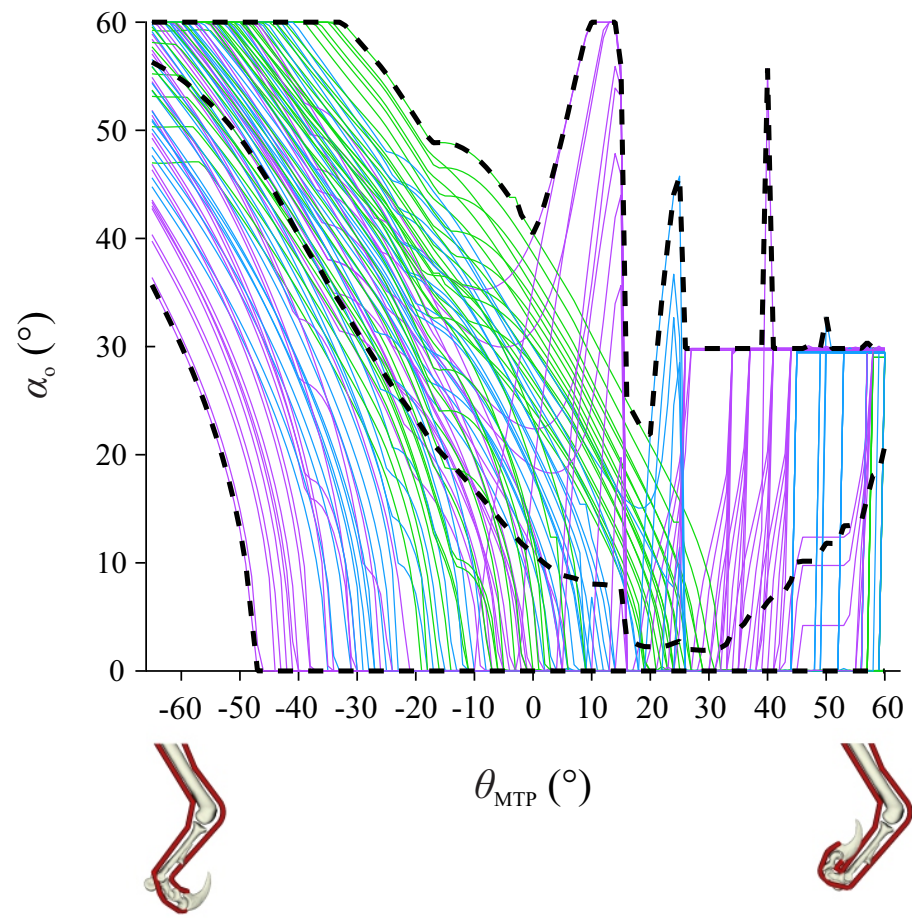
Figure 6 (on next page)

Optimization results for the four sensitivity analyses, showing clawforce $\left(F_{\text {claw }}\right)$ plottedagainst metatarsophalangeal joint angle $\left(\theta_{\text {MTP }}\right)$.

(A) More constrained operating range for muscle fibres. (B) Extensor muscle actively contracting in holding digit II off the ground. (C) Muscle strength is doubled. (D) More restrictive bounds on the allowable range of pennation angles in the optimization. All results are parsed by posture. Curves show the mean values, shaded regions denote total range, and crosses denote maxima for each of the 108 curves that are represented in the plots. 
A

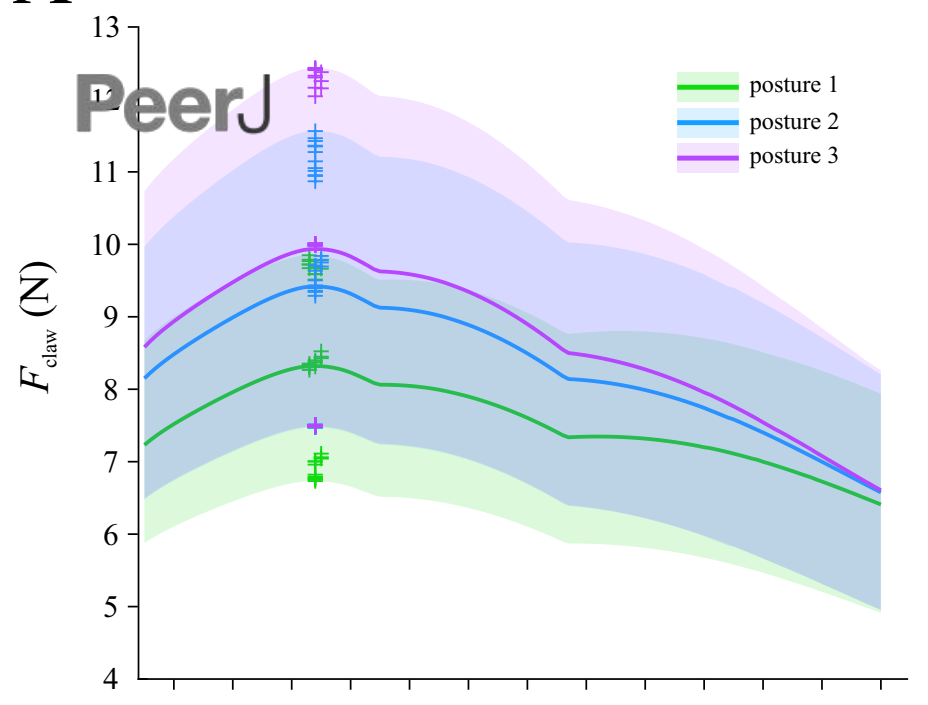

C

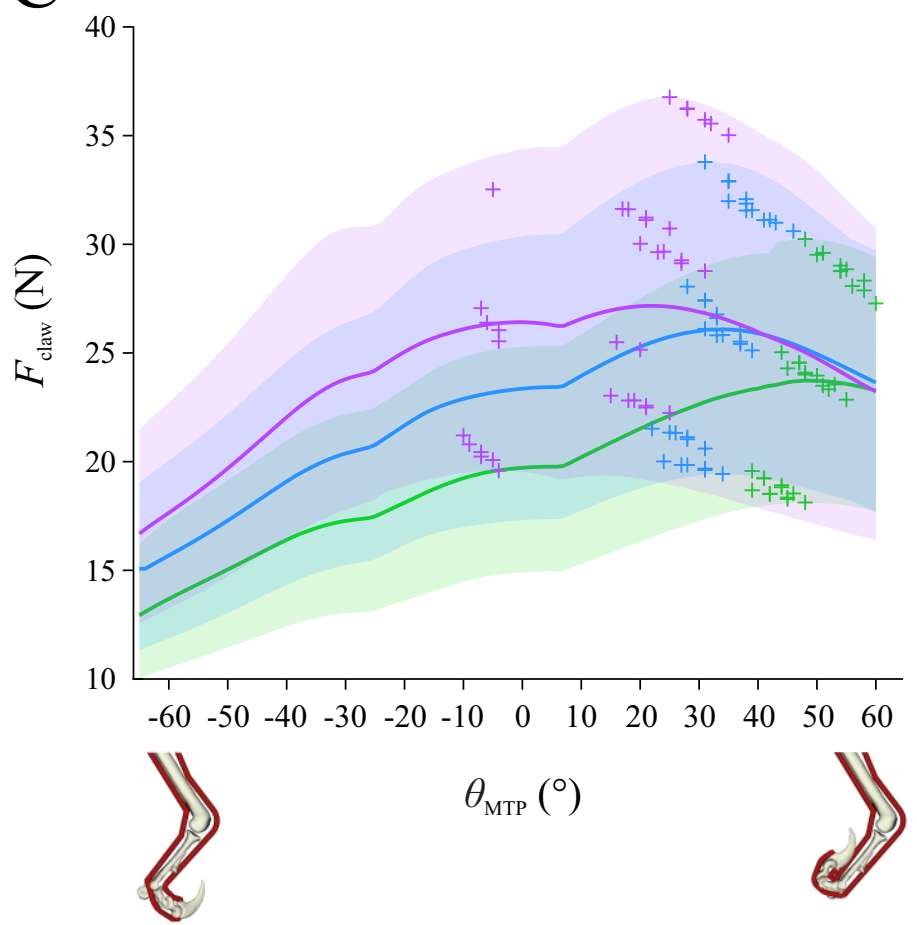

B

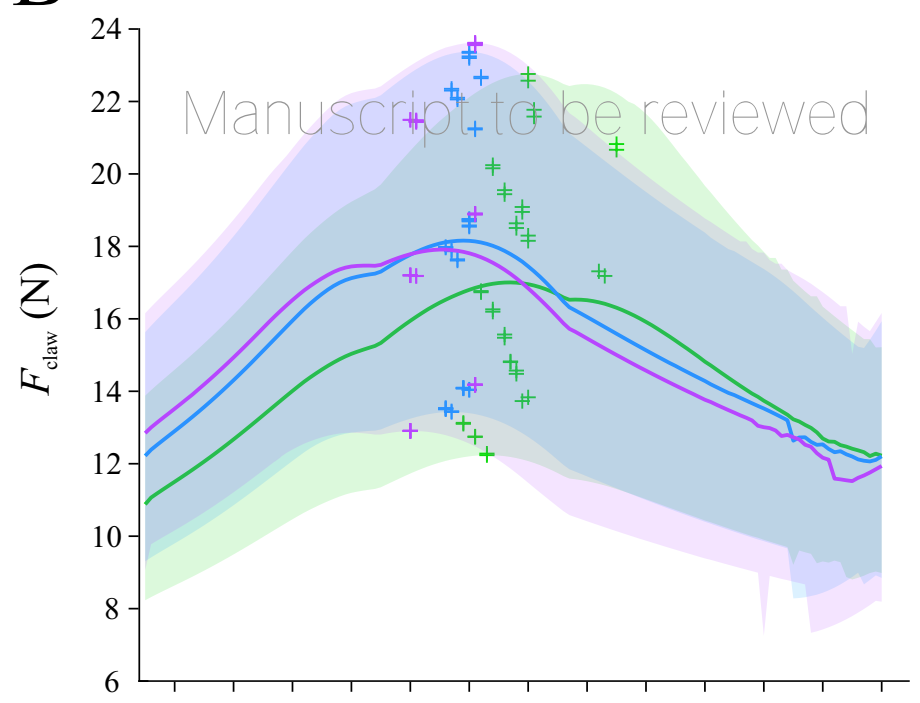

D

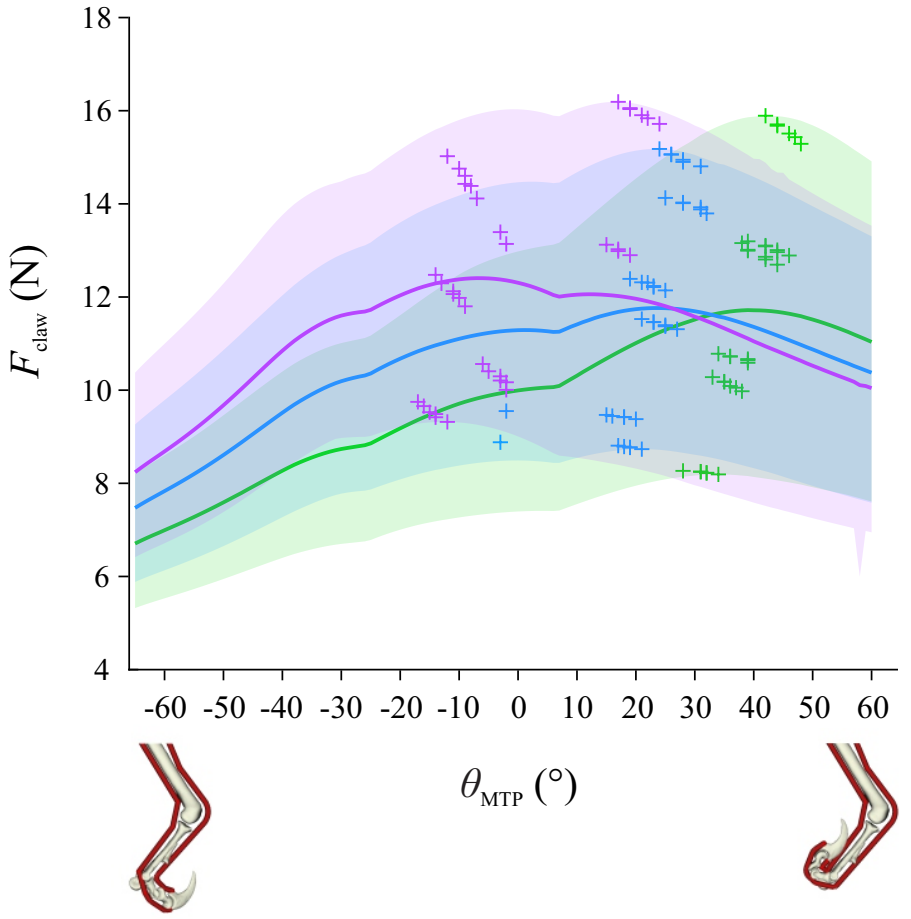




\section{Table 1 (on next page)}

Parameters defining the different variations in the model tested, aswell as the bounds on the design variables during the optimization.

Postural angles are measured relative to the model's 'neutral posture', which is where the limb is fully straightened. Note that thigh angle is only used to reorient the model with respect to the global coordinate system. 
1 Table 1. Parameters defining the different variations in the model tested, as well as the bounds on 2 the design variables during the optimization. Postural angles are measured relative to the model's 3 'neutral posture', which is where the limb is fully straightened. Note that thigh angle is only used 4 to reorient the model with respect to the global coordinate system.

5

6

7

8

9

10

11

12

13

14

15

16

17

18

19

20

21

22

\begin{tabular}{|c|c|c|c|}
\hline Parameter & Posture 1 & Posture 2 & Posture 3 \\
\hline Thigh angle $\left(^{\circ}\right)$ & -15 & -40 & -65 \\
\hline Knee angle $\left({ }^{\circ}\right)$ & -25 & -70 & -115 \\
\hline Ankle angle $\left(^{\circ}\right)$ & 20 & 70 & 120 \\
\hline Threshold MTP angle $\left(^{\circ}\right)$ & 35 & 25 & 15 \\
\hline Threshold moment (Nm) & -0.02529 & -0.02823 & -0.02866 \\
\hline$\ell_{\mathrm{o}}$ lower bounds $(\mathrm{m})$ & \multicolumn{3}{|c|}{0.02} \\
\hline$\ell_{\mathrm{o}}$ upper bounds (m) & \multicolumn{3}{|c|}{0.65} \\
\hline$L_{\mathrm{s}}$ lower bounds (m) & \multicolumn{3}{|c|}{0.191 (extensor), 0.237 (flexor) } \\
\hline$L_{\mathrm{s}}$ upper bounds $(\mathrm{m})$ & \multicolumn{3}{|c|}{$\begin{array}{l}\text { long MTU: } 0.423 \text { (extensor), } 0.471 \text { (flexor) } \\
\text { short MTU: } 0.311 \text { (extensor), } 0.369 \text { (flexor) }\end{array}$} \\
\hline$\alpha_{0}$ lower bounds $\left({ }^{\circ}\right)$ & \multicolumn{3}{|c|}{$0^{*}$} \\
\hline$\alpha_{\mathrm{o}}$ upper bounds $\left(^{\circ}\right)$ & \multicolumn{3}{|c|}{$60^{*}$} \\
\hline
\end{tabular}

$* 20-35^{\circ}$ in sensitivity analysis. 


\section{Table 2 (on next page)}

Assessment of how well supported each behavioural hypothesis is by theresults of the present study.

As hypotheses have not been previously described in an explicitly quantitative manner, they are codified here in a qualitative fashion only. 
1 Table 2. Assessment of how well supported each behavioural hypothesis is by the results of the 2 present study. As hypotheses have not been previously described in an explicitly quantitative 3 manner, they are codified here in a qualitative fashion only.

\begin{tabular}{|c|c|c|c|c|}
\hline Hypothesis & Whole-limb posture & Digit posture & $\begin{array}{l}\text { Force required at } \\
\text { claw tip }\end{array}$ & Supported? \\
\hline $\begin{array}{l}\text { slash-kicking prey } \\
\text { (Fig. 1B) }\end{array}$ & extended & extended & high & no \\
\hline $\begin{array}{l}\text { prey riding } \\
\text { (Fig. 1C) }\end{array}$ & $\begin{array}{l}\text { extended to semi- } \\
\text { flexed }\end{array}$ & $\begin{array}{l}\text { moderately } \\
\text { extended }\end{array}$ & high & no \\
\hline $\begin{array}{l}\text { prey-mounted flank attack } \\
\text { (Fig. 1D) }\end{array}$ & $\begin{array}{l}\text { extended to semi- } \\
\text { flexed }\end{array}$ & $\begin{array}{l}\text { moderately } \\
\text { extended }\end{array}$ & high & no \\
\hline $\begin{array}{l}\text { targeting prey's vital areas } \\
\text { (Fig. 1E) }\end{array}$ & semi-flexed to flexed & variable & $\begin{array}{l}\text { variable (depending } \\
\text { on substrate) }\end{array}$ & partly \\
\hline $\begin{array}{l}\text { prey restraint } \\
\text { (Fig. 1F) }\end{array}$ & flexed & flexed & low & yes \\
\hline $\begin{array}{l}\text { kicking defence } \\
\text { (Fig. 1G) }\end{array}$ & extended & extended & high & no \\
\hline $\begin{array}{l}\text { digging out prey } \\
\text { (Fig. } 1 \mathrm{H})\end{array}$ & $\begin{array}{l}\text { extended to semi- } \\
\text { flexed }\end{array}$ & flexed & $\begin{array}{l}\text { variable (depending on } \\
\text { substrate) }\end{array}$ & partly \\
\hline
\end{tabular}

4

5

6

7

8

9

10

11

12

13

14

15

16

17

18

19 